\title{
Arquitectura pública: proyectos del Estado en la poscrisis argentina de 2001
}

Julio Arroyo

Arquitecto. Profesor de Proyecto, Teoría y Crítica de la Arquitectura y la Ciudad Contemporánea. Facultad de Arquitectura, Diseño y Urbanismo, Universidad Nacional del Litoral, Argentina. jarroyo47@hotmail.com

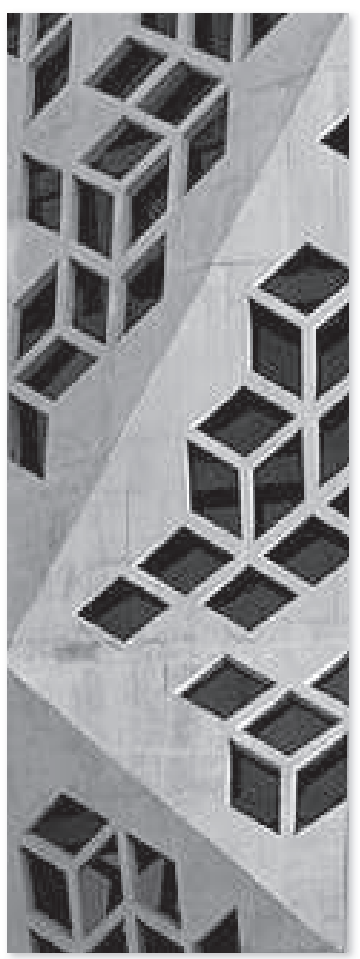




\title{
Resumen
}

El Estado en Argentina es una institución socio-política con una larga tradición en la promoción, gestión y encomienda de obras de arquitectura destinadas a los equipamientos necesarios para el sostenimiento y desarrollo de la sociedad. Con este texto se propone una reflexión sobre la generación del dominio público basada en una investigación sobre la producción arquitectónica del Estado en cualquiera de sus niveles (nacional, provincial o municipal) durante el período 2003-2011. En este lapso se superó la crisis de diciembre de 2001 y transcurre un ciclo de activación de la dimensión política y recuperación económica del país, cuya incidencia en la arquitectura y la ciudad se pretende revisar. El resultado de la investigación se sintetiza en una base de datos geo-referenciada de obras relevantes de arquitectura pública y en una serie de reflexiones en torno a la producción del período. Este trabajo contribuye, en particular, a este último aspecto.

\section{Palabras clave}

Arquitectura; edificios públicos; espacio público; ciudad; equipamientos.

\begin{abstract}
Public architecture: state public works in the argentinean post-crisis of 2001. The State in Argentina is a socio-political institution with a long tradition in the promotion, management and entrustment of architectural works needed for social development. This paper reflects upon the generation of these works in the public realm based on research of the architectural production of the State at national, provincial or municipal levels during the period 2003-2011. We intend to consider how, during this period, public actions impacted architecture and the city, when the crisis of December 2001 was overcome and the cycle of activation of the political dimension and economic recovery of the country began, The result of the research is synthesized in a geo-referenced database of relevant works of public architecture and in a series of reflections on the production of the period. This work contributes to this latter aspect.
\end{abstract}

\section{Keywords}

Architecture; public buildings; public space; city; social facilities. 
"El encargo como un problema de poder, entonces, y la arquitectura como un problema intelectual son las dos partes de una ecuación que siempre implica una dimensión ética."

(BALLENT y GoReliK, 2000: 6)

\section{Contexto}

La investigación en la cual se enmarca este artículo se ubica temporalmente en la poscrisis argentina, período que sucede a la debacle política, social, económica y financiera que hizo eclosión en diciembre de 2001 y que se extendió por varios años. La república se tambaleó en razón del quiebre de la economía, lo que se tradujo en una serie de medidas que afectaron profundamente a la sociedad y llevaron a una generalizada movilización ciudadana que derivó en saqueos y airadas manifestaciones callejeras de distintos estamentos de la sociedad. La eclosión de los acontecimientos se dio entre los días 19 y 21 de diciembre, cuando el conflicto se agravó aún más con la declaración del estado de sitio. En esos días aciagos las mayores manifestaciones se produjeron en la Plaza de Mayo de Buenos Aires, reprimidas por la policía con consecuencias trágicas. Los hechos precipitaron la renuncia del presidente Fernando de La Rúa y con ello la instalación de un clima caracterizado por un estado aún mayor de alteración e incertidumbre de la población. En el plano político se suscitó una inaudita coyuntura institucional, ya que hubo sucesivos recambios presidenciales en pocos días. La gravedad de la situación pudo sortearse, no obstante, dentro de los márgenes de la Constitución, cuestión no menor en un país con nefastos antecedentes de golpes de estado.

Toda crisis es interesante, sobre todo cuando una leve mejoría permite avizorar mejor el panorama, dice Luis Alberto Romero (2003). El panorama de la poscrisis es ambiguo, un tiempo impreciso en el que coexisten las frustraciones y las expectativas. Pueden diferenciarse dos momentos: el inmediato limitado a la presidencia de Eduardo Duhalde y el mediato, que se inicia con la presidencia de Néstor Kirchner en 2003. Con Duhalde se logró salir de la llamada convertibilidad, sanear mínimamente la economía y recuperar gobernabilidad e institucionalidad. Con Kirchner se inauguró un ciclo que se extendería por tres mandatos, dado que a su presidencia le sucedió la de su esposa, Cristina Fernández, quien gobernó por dos períodos hasta 2015. 
La investigación toma como período de estudio el correspondiente al segundo momento y en particular a las presidencias de Néstor Kirchner (2003-2007) y Cristina Fernández de Kirchner (primer mandato, entre 2007 y 2011), tiempo durante el cual se articula un discurso oficial basado en el ataque al neoliberalismo y la hegemonía del mercado de la década de los 90, y en un progresismo de corte populista que recupera, en el plano político, la mística de la militancia de los años 70, la defensa de los derechos humanos de los 80, la revisión de las leyes de Obediencia Final y de Amnistía de los 90 y la autonomía regional respecto de los países centrales, entre otros elementos propios de la primera década de este siglo (Romero, 2013).

En el plano social, se procuró la inclusión de los sectores pobres - mayormente urbanosmediante la subsidiariedad focalizada, la ampliación de la cobertura social y el estímulo al empleo, que permitió el acceso al consumo de bienes y servicios de segmentos sociales postergados. También se dictaron leyes que beneficiarían a las minorías no reconocidas. En el económico, el gobierno procuró el desendeudamiento externo y el incremento de los recursos como consecuencia de superávit de comercio exterior y fiscal con el objetivo de hacer una redistribución con sentido de justicia social. Esto fue posible en razón de ciertos factores de la economía global que, de manera muy oportuna, llevaron a un incremento repentino de la demanda, y consecuentemente de los precios de los commodities. Esto último dio lugar a una política de retenciones a la renta agraria extraordinaria que le permitió al país recuperar rápidamente sus reservas monetarias, con lo cual el gobierno nacional incrementó notablemente su capacidad de producción de obra pública (CEPAL, 2010).

Se verificó también un proceso de alta concentración de recursos fiscales en manos del gobierno nacional, cuyas autoridades dispusieron de facultades legales para hacer un manejo del presupuesto de gastos con amplio margen de discrecionalidad. Esta circunstancia de alta concentración de recursos económicos y poder político en la esfera del gobierno nacional interesa directamente a la investigación, por cuanto constituye la condición de posibilidad para las políticas de dotación de equipamientos sociales de variada índole funcional que caracterizaron estos períodos presidenciales.

En el orden internacional, los gobiernos kirchneristas se alinearon con otros de la región en la confrontación y denuncia de las políticas neoliberales y las instituciones supranacionales que las sostuvieron en la década de los 90, y conformaron un bloque entre Brasil, Venezuela, Ecuador, Bolivia, Uruguay y Argentina que trabajó — con sus matices propios- con un sentido de desarrollo social equitativo. 
Arquitectura pública: proyectos del Estado en la poscrisis argentina de 2001

En Argentina, el presidencialismo se ha ido profundizando como rasgo característico de la política nacional desde la recuperación de la constitucionalidad en 1983. En este período, dicha tendencia se refuerza debido a un estilo de gobierno fuertemente personalista tanto de las autoridades nacionales como de algunas provincias, lo que implicó una tensión entre Estado y Gobierno (Bоввіо ET ÁL., 2005). La tensión puede explicarse como una confrontación conceptual entre los fines y objetivos abstractos y generales de las instituciones del Estado republicano, que se instalan en un horizonte temporal extendido en pos de políticas de largo alcance, y los intereses concretos, más urgentes y ajustados a los ciclos electorales a los que se ciñen las autoridades de turno, máxime en tiempos políticos tan enervados como los que vivió - y continúa viviendo- la Argentina, fuertemente polarizada como sociedad.

Los nuevos equipamientos se inscribieron mayormente en una planificación centralizada en la jurisdicción federal, aunque concertada con los gobiernos provinciales o bien en los propios estados provinciales. El vasto conjunto de obras públicas resultante debe ser comprendido en el contexto de una sociedad fuertemente sumida en el debate político, lo cual significó que ciertos sectores vieran allí la concreción de genuinos actos de gobierno y, otros, meras operaciones propagandísticas de los gobernantes. No obstante, los equipamientos que se construyeron ampliaron, objetivamente y de manera notable, el parque de escuelas, hospitales, centros cívicos y culturales, edificios institucionales y espacios verdes que conforman el dominio público, distribuidos por todo el territorio nacional, si bien de manera diferenciada según el mapa de afinidades políticas de los gobiernos provinciales respecto del central. Si bien las provincias políticamente afines al gobierno central se vieron más beneficiadas, no es menos cierto que el clima de crecimiento económico de esos años alentó en general las obras púbicas en todo el país. Como particularidad, fue reiterado que los municipios recibieran recursos directamente del Estado nacional, sin pasar por el nivel provincial.

En breve, se trata de un período altamente controversial no solo en términos de debate político-ideológico, sino también por el peso del presidencialismo y el estilo kirchnerista de gobierno; no obstante, cabe destacar la notoria recuperación del protagonismo del Estado en la vida nacional y la generación de condiciones objetivas para la producción de una significativa cantidad de obras de arquitectura pública que vinieron a satisfacer demandas reales de la sociedad. Esta circunstancia histórica es la que promueve algunos interrogantes que dan pie a la investigación. 


\section{Problemática}

Una serie de interrogantes conforman el núcleo problemático de la investigación. El más general es acerca de la apelación que hace el Estado/gobierno a la arquitectura en relación con la ciudad: ¿cómo es la relación entre el edificio público, en tanto obra de alto valor simbólico, y la ciudad escindida como condición de la urbanidad contemporánea, en el marco de la reactivación de la economía y la política que atraviesa la sociedad en el período?

El Estado ha tenido históricamente una incidencia determinante en la definición del dominio público de la ciudad argentina, mediante la dotación de edificios institucionales y la sistematización de espacios exteriores urbanos, como plazas, parques, etc. La pregunta parte de reconocer esta tradición de Estado proveedor o de bienestar (las diferencias entre estas distintas conceptualizaciones del Estado no son objeto de este texto), pero se problematiza al observarse que, en la ciudad contemporánea en general, la capacidad de los equipamientos públicos de generar lugares, topologías y territorios, de estructurar y jerarquizar la extensión urbana, se pone en cuestión. Esto adquiere especiales connotaciones si se tiene en cuenta que el porcentaje de población urbana en Argentina asciende al 92 \% (según INDEC ).

El presupuesto de este interrogante es que los edificios y, en general, la obra pública de arquitectura constituyen núcleos de centralidad en la ciudad al diferenciarse de la edilicia ordinaria por la función, la imagen institucional o la escala del servicio. Se espera que un edificio público potencie o induzca centralidad urbana y contribuya a la generación de una topología de la ciudad definida por lugares significativos. Los lugares públicos asociados a escuelas, hospitales, centros vecinales, etc., profundizan —en sus diversas escalas- la experiencia de la densidad y la intensidad, características propias de la centralidad. La densidad viene dada por la mayor concentración relativa — espacial y temporal— de actividades y personas; la intensidad, por la mayor carga de estímulos, niveles de interacción, oportunidades de intercambios, etc., lo cual explica los atributos de los buenos lugares urbanos, que se caracterizan por generar efectos de referencia, identidad y memoria en la sociedad.

La dotación de equipamientos producidos por el Estado consolida el dominio o territorio público y refuerza el concepto, la imagen y la valoración social del espacio urbano público. El espacio público se caracteriza por ser el ámbito $a$ ) común, donde la ciudadanía se expresa y actúa democráticamente; $b$ ) general, puesto que atañe e involucra a la totalidad de la 
población urbana; c) colectivo, ya que su uso y disfrute es inexorablemente compartido y d) jerárquico, porque responde a una axiología de virtudes cívicas y ciudadanas que allí se expresan, sobreponiéndose a los intereses particulares (BorJA, 2003; CARRIón, 2007; García CAnClini, 2005; Montaner y Muxí, 2011).

Este presupuesto de edificio o lugar público como factor de centralidad y constitución de lugares relevantes en la ciudad es, precisamente, lo que se pone en cuestión en la ciudad actual, que se reproduce bajo las formas del capitalismo financiero trasnacional, las economías globalizadas, la informatización de los procesos productivos y el trabajo posfordista, las organizaciones en red y la circulación en tiempo breve y a gran escala de grandes flujos de elementos materiales e inmateriales (Hall, 1996; Castells, 1998, Harvey, 2004, 2012; Soja, 2010; Montaner y Muxí, 2011). Estos procesos de escala macro condicionan los procesos urbanos, a la vez que se hacen específicos en la vida cotidiana de las ciudades, enervando la experiencia de lo que es próximo en tiempo y espacio - lo local—, es decir, generando una experiencia que, respondiendo en gran medida a factores exógenos, impacta y es abordada material y simbólicamente como si de procesos endógenos se tratara.

La ciudad escindida, por su parte, es una hipótesis ya trabajada (ARroyo, 2006, 2011) que se retoma como premisa de la investigación. Zigmunt BAUMAn brinda elementos que explican la escisión al desarrollar el concepto de modernidad fluida (2000). BAUMAn expresa que "lo que se ha roto ya no puede ser pegado y llama a abandonar toda esperanza de unidad. La ciudad es precisamente la ciudad que se ha roto, que ha perdido su condición ontológica de ser una unidad o totalidad sea dialéctica o sistémica, estructural o fragmentaria”. La escisión se define como un proceso en curso - observable y experimentable- de disyunción de la ciudad física, social y política (urbs, civitas y polis) (ARRoyo, 2016). Se pone de manifiesto en espacios físicos discontinuos, prácticas sociales disruptivas e intempestivas y significados relativos a lo público no universales sino eventuales y contingentes, pero sobre todo en la dificultad para definir ontológicamente la ciudad como una totalidad de sentido único (2016).

Las condiciones objetivas de la escisión urbana radican en procesos diversos pero convergentes, tales como las economías de servicios y las formas de producción y trabajo posfordistas; la crisis de representatividad y valores de las democracias republicanas, la vulnerabilidad ambiental consecuencia de urbanizaciones desaprensivas respecto del soporte natural y geográfico; la incidencia extensiva y generalizada de la informática y las tecnolo- 
gías de comunicación que cambian los modos personales de percibir, comprender, valorar y relacionarse en el espacio y el tiempo; el desarrollo del consumo y el ocio programado y de los media como ámbitos de generación de modelos de referencia y de opinión. La ciudad escindida es una tensión constante entre lo múltiple, concomitante con una sociedad en la que prevalece el individuo antes que el ciudadano, sociedad afectada por estilos de vida privatistas y hedonistas, por segregaciones y exclusiones, factores todos que impiden la construcción del espacio público.

El espacio público es una materialización de las ideologías que anidan en una sociedad (Delgado, 2010) y, por lo mismo, el ámbito de manifestación de las resistencias. Tal vez la particularidad de la ciudad escindida es que las estructuras originadas en clases sociales antagónicas se debilitan frente a la sociedad de individuos en la cual "el espacio público no es mucho más que una pantalla gigante sobre la que son proyectadas las preocupaciones privadas sin dejar de ser privadas ni adquirir nuevos valores colectivos durante el curso de su proyección: el espacio público es donde se realiza la concesión pública de los efectos e intimidades privados” (BAUMAN, 2000: 45).

Más allá del discurso político hegemónico del período, la sociedad argentina no ha escapado de estas tendencias que describe BAUMAN, quien ve el presente no como una situación posmoderna, con lo que de superado o sustancialmente diferente pudiera significar, sino como una modernidad diferente. Esta diferencia radica en dos aspectos novedosos: el gradual colapso y decadencia de la ilusión de un telos de camino histórico alcanzable que lleva a una sociedad buena, justa y sin conflictos y la desregulación y la privatización de las tareas y responsabilidades de la modernización, por lo cual aquello que era considerado un trabajo a ser realizado por la razón en tanto atributo y propiedad de la especie humana ha sido fragmentado ('individualizado'), dejado en manos de los individuos y de sus recursos individualmente administrados" (2006: 43).

La ausencia de un fin y el sentido individualista de la acción colectiva sintetizan el tiempo que vivimos. Ello constituye el plano de fondo de la ciudad escindida, en la cual las relaciones entre lo material de la urbs, lo socio-humano de la civitas y lo simbólico de la polis se distorsionan en la eventualidad y la contingencia de las relaciones ligadas a procesos e intereses segmentados y discontinuos, movidas por procesos no lineales, sujetas a lo probable antes que a lo posible, con regularidades locales antes que globales. Los atributos del 
espacio público urbano se debilitan en la creciente discontinuidad física, observables en el incremento de barreras materiales y fronteras morales y en territorios de exclusión, enclaves de creciente consolidación. También, en la discontinuidad social dada por los procesos de segregación, exclusión, gentrificación, marginación social que generan guetos, ciudades ocultas, periferias a la vez que espacios de elite, con secuelas de prácticas desagregadas e intempestivas en el espacio urbano. En el plano político-cultural se observa en la discontinuidad axiológica en consonancia con la multiplicación de subjetividades urbanas no asociadas a clases, sino a estamentos y grupos de interés.

En la ciudad argentina de la poscrisis, nuevos sujetos urbanos introducen no solo prácticas novedosas, sino también intereses que se explican desde la dispersión social del conflicto antes que por la praxis política social fundada en intereses de clase (RomERo, 2013). El espacio público se desvanece como ámbito común, general, colectivo y jerárquico, con lo cual entran en crisis tanto la ética ciudadana de republicanismo de cuño liberal como la praxis social de raíz materialista. En cualquier caso, la presunción de un sujeto autoconsciente de la teleología de la historia naufraga en la puja de intereses sectoriales que se materializan en tácticas, oportunistas, cortoplacistas y reductivamente pragmáticas.

\section{Equipamientos}

La referencia empírica de estas preguntas son los equipamientos arquitectónicamente producidos en el período desde la esfera del Estado. Los equipamientos urbanos son edificios o espacio exteriores, de dominio estatal o privado, acondicionados para el desarrollo de actividades necesarias para el sostenimiento, desarrollo, promoción y bienestar de la población en general y de la sociedad urbana en particular. Cubren un amplio espectro de funciones relativas a salud, educación, gobierno, justicia, seguridad, esparcimiento, culto, deporte y comunicaciones. Junto con las infraestructuras y los servicios constituyen las provisiones necesarias para garantizar calidad de vida a la población. Según el destino de uso y el sentido con que se producen, los equipamientos admiten el calificativo de públicos, sociales, urbanos, colectivos o comunitarios (Franco Calderón y Zabala Corredor, 2012; Hernández Aja, 2000).

En el marco de la investigación, se han clasificado los casos según el siguiente criterio:

- Equipamientos básicos. Son los que acompañan el crecimiento demográfico vegetativo 
y responden a necesidades básicas y fundamentales de la población. Conforman un vasto parque edilicio de dominio público en el que se inscriben escuelas, centros de salud, comisarías, etc. Corresponden a programas masivos de gobierno que, en el período en estudio, estuvieron altamente concentrados en la jurisdicción nacional, especialmente en los aspectos económico-financieros. En algunos casos, si bien los programas eran nacionales, el proyecto y ejecución de las obras se realizó de manera descentralizada, con participación de recursos y estructuras administrativas provinciales o municipales. Como herencia de los años 90, subsistieron las unidades ejecutoras de conformidad con las exigencias de los organismos internacionales de financiación, a la par de las oficinas técnicas tradicionales del Estado. Se trata de obras que por su función y escala tienden a una localización dispersa en la ciudad, formando redes territoriales. Por lo tanto, el impacto de estas obras debe medirse en la escala próxima de lo barrial, en el valor de cohesión social y en la connotación simbólica de institucionalidad estatal, de lo cívico y lo social.

- Equipamientos singulares. Son edificios y espacios únicos o excepcionales que se justifican en la necesidad de facilitar servicios especiales. Tienen un impacto de mayor escala tanto en el orden material como en el simbólico. Alojan funciones relevantes, tales como centros culturales, hospitales, parques, aeropuertos, estadios, instalaciones deportivas, etc. Además de su jerarquía por escala y función, brindan una imagen diferenciada capaz de calificar por sí misma el entorno urbano de localización. Son oportunidades excepcionales para la reflexión y la práctica de la arquitectura, y es común que el proyecto se origine en concursos profesionales. Con estos edificios especiales el Estado ejerce una presencia retórica, dado su alto potencial de representación de los valores cívicos, aunque en ocasiones quedaron reducidos a meros instrumentos propagandísticos.

- Equipamientos especiales y efímeros. Se asocian a ocasiones excepcionales, tales como celebraciones o conmemoraciones especiales: efemérides históricas, memoriales, monumentos, parques conmemorativos, etc. En estas obras el Estado se asume como promotor de una narrativa de integración y unidad social capaz de neutralizar los conflictos coyunturales y magnificar los grandes relatos de la nacionalidad, que demandan a la arquitectura su más alta capacidad de representación simbólica.

Metodológicamente, la investigación reconoce dos fuentes de información: a) publicaciones gráficas (suplementos de diarios, revistas especializadas) y digitales (portales y revistas 
electrónicas) de las obras; estas fuentes se ampliaron en algunos casos que se presentan a continuación a textos tales como discursos oficiales, informes técnicos o memorias de proyecto, y $b$ ) encuestas a informantes calificados (presidentes de colegios profesionales, profesores e investigadores de facultades de Arquitectura). Con esta información se procedió a confeccionar una base de datos geo-referenciada que incluye más de 150 obras. Por una razón de dimensión de las muestras, se limitó el relevamiento a equipamientos singulares y especiales y efímeros, decisión que dejó afuera del mapeo a una gran cantidad de obras producidas en el marco de programas masivos, como es el caso del Plan Federal de Viviendas o del Plan 700 Escuelas, los cuales ameritan una investigación en particular. Sobre esta base de relevamientos se practicó una selección de casos que se presentan a título ilustrativo y que luego dan lugar a algunas consideraciones.

\section{Casos}

Fueron seleccionados ocho casos: cinco son equipamientos destinados a cultura, justicia y gobierno, uno es un parque memorial y dos son obras temporarias. Cuatro son obras nacionales, uno es municipal y tres pertenecen a provincias. A continuación se describen brevemente los casos.

\section{Centro Cultural del Bicentenario,} luego denominado Centro Cultural Néstor Kirchner (CCK)

La principal obra conmemorativa del Bicentenario de la Emancipación Nacional de 2010 consiste en la refuncionalización y puesta en valor de un edificio representativo, paradójicamente, del primer Centenario. El Estado kirchnerista apela a la arquitectura palaciega del Beaux Art, representativa de un momento de la historia nacional con el cual ha confrontado ideológicamente el peronismo, para una celebración que debería pensar el futuro de la nación a través de la arquitectura. El antiguo Palacio de Correos, proyectado por el Arq. Norbert Maillart en 1888, revisado en 1908 e inaugurado con grandes cambios recién en 1926, recibe un programa que contiene una gran sala sinfónica, auditorios aptos para todo tipo de géneros musicales, salas de exposiciones y amplias terrazas miradores. El proyecto fue promovido por una comisión ad hoc que realizó consultas públicas para definir el destino 


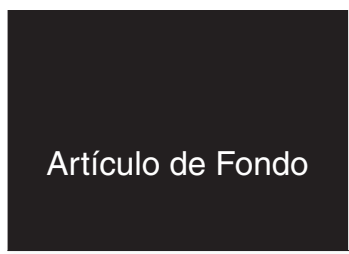

Julio Arroyo

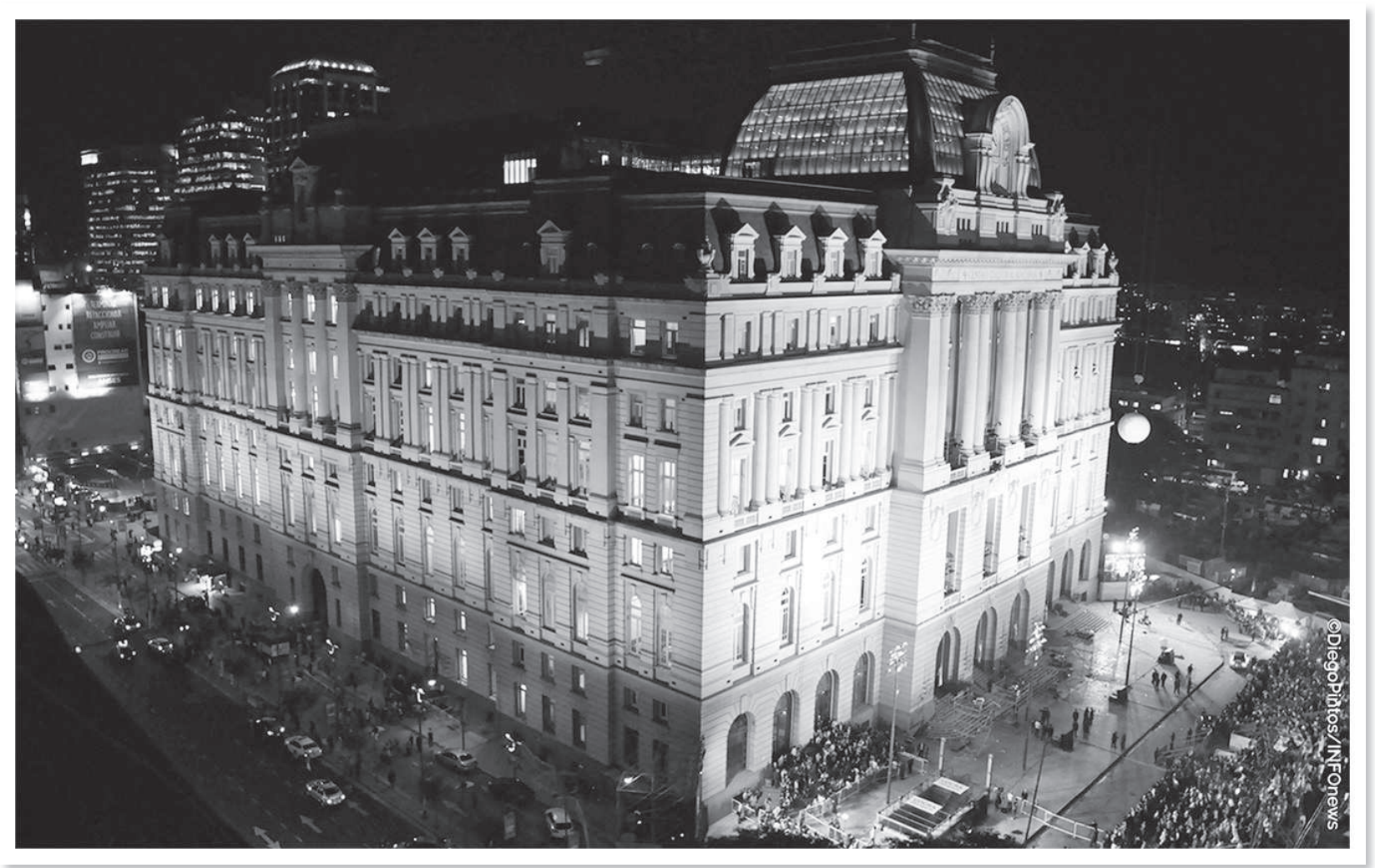

Centro Cultural

del Bicentenario,

luego denominado Centro Cultural Néstor Kirchner de uso del edificio e incluso convocó a estudios internacionales. También tuvieron participación la Universidad de Buenos Aires, entidades profesionales y la Comisión de Museos, Monumentos y Sitios Históricos, entidad esta que estableció las condiciones de intervención desde un punto de vista del resguardo patrimonial. Con posterioridad, el gobierno nacional convocó a un concurso internacional que fue ganado por el estudio de los arquitectos Enrique Bares, Federico Bares, Nicolás Bares y Daniel Becker, asociado al de Claudio Ferrari y Florencia Schnack (figura 1). 
Arquitectura pública: proyectos del Estado en la poscrisis argentina de २००1

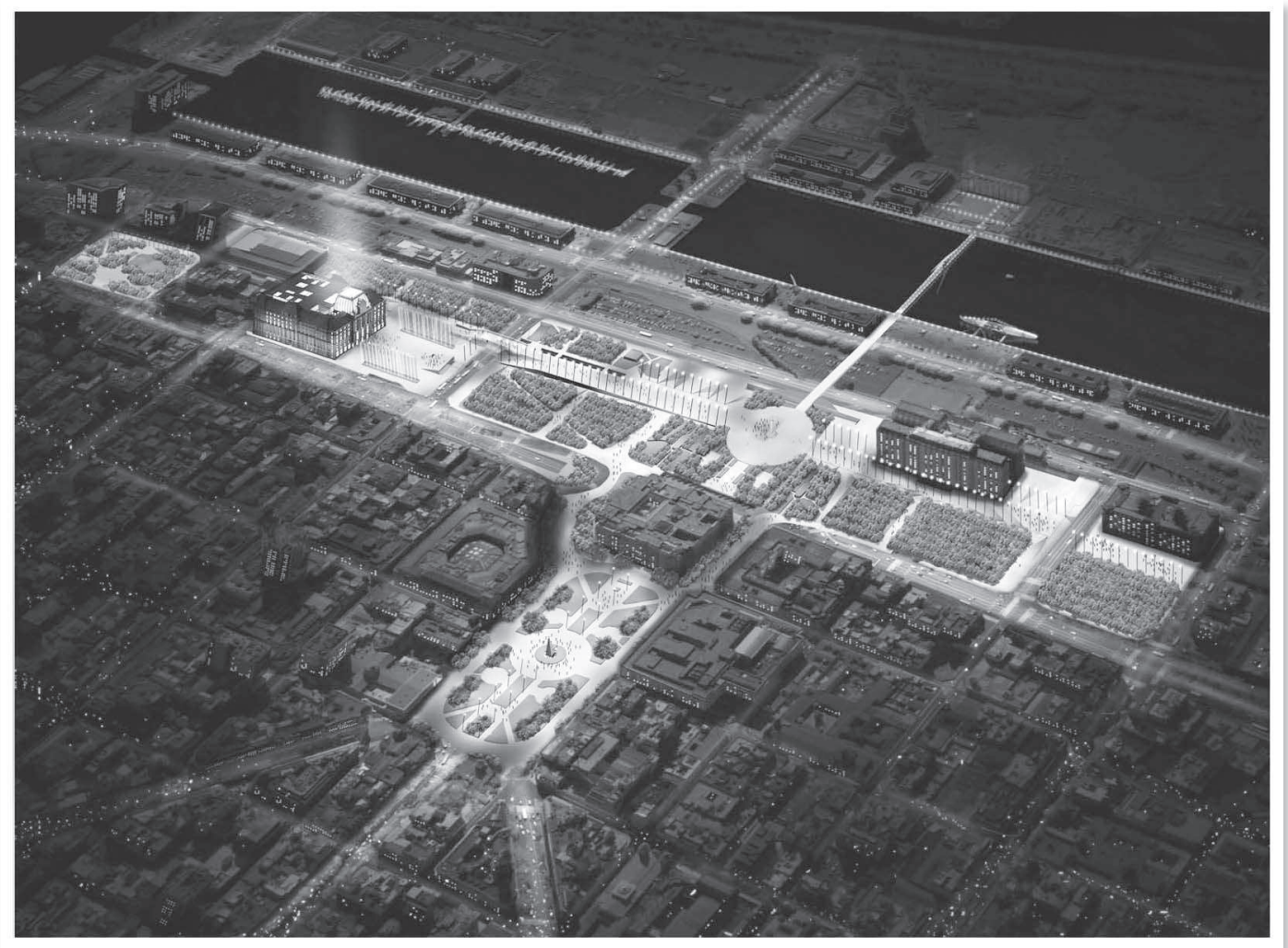

Figura 1. Centralidad cívica: Plaza de Mayo, Casa Rosada, Centro Cultural, Museo y Parque del Bicentenario. Autores: B4FS, 2010. Arqs. E. Bares, F. Bares, N. Bares y D. Becker con C. Ferrari y F. Schnack

Fuente: SILVESTRI, G. Palacio de Correos. Proyecto Centro Cultural del Bicentenario. Memorias, ideas, futuro. Bs. As., Proyecto CCB, 2007 
En la escala edilicia el proyecto se ordena según dos criterios: puesta en valor de las partes nobles y vaciado del sector llamado "industrial", en el que se realizaban las actividades técnicas y logísticas del correo, para alojar el conjunto de elementos que metafóricamente se denominan la terraza, el chantellier, la ballena y las salas. La imagen de la izquierda muestra estos elementos agregados en el patio central, que fue ampliado para recibirlos. El acceso a las terrazas y, de manera especial, la habilitación al uso público de la mansarda acristalada permitirán un inédito relacionamiento del palacio con la ciudad (figura 2).

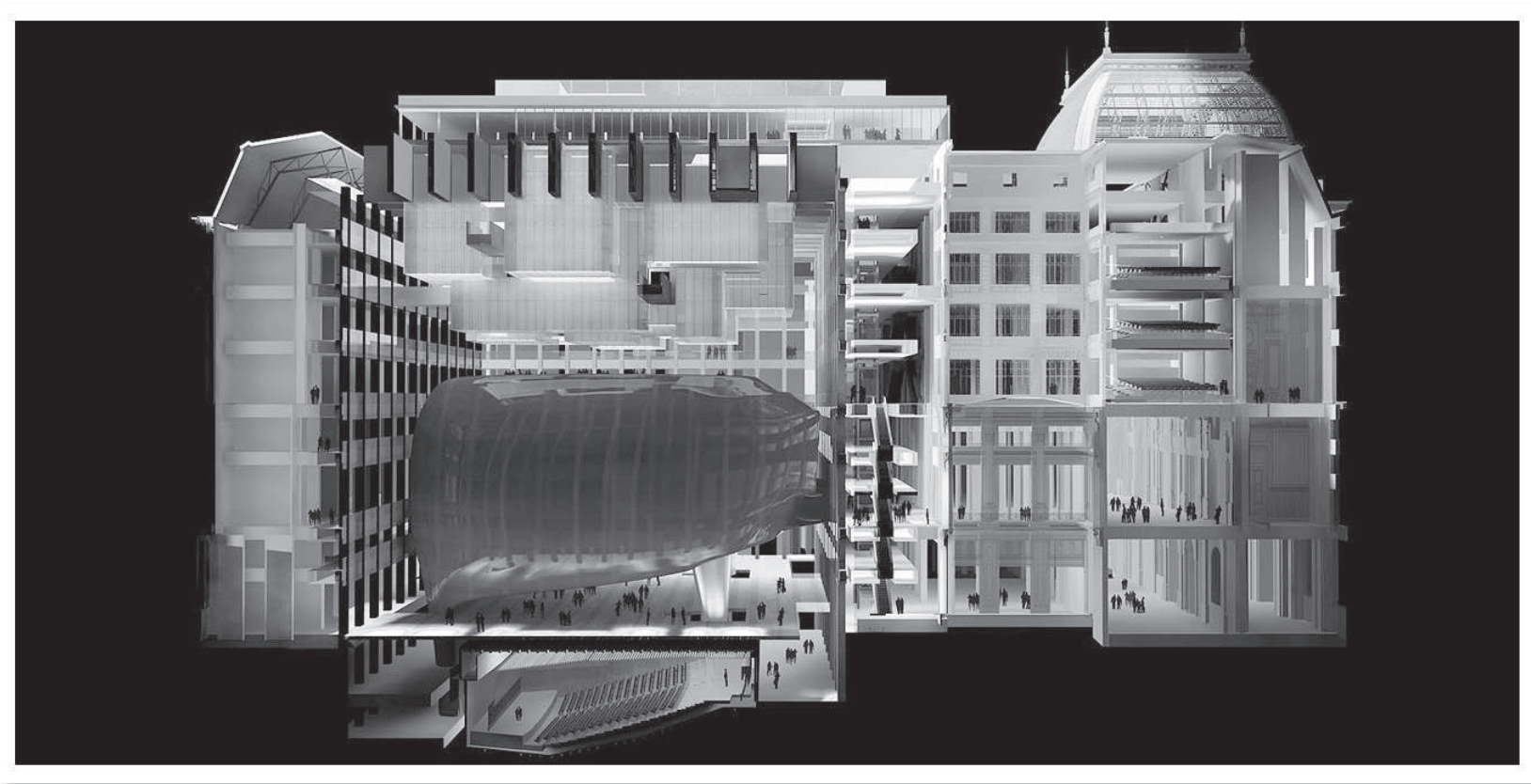

Figura 2. Proyecto. Restauración de partes nobles (cuerpo de la derecha) y ampliacion en el cuerpo "industrial" (izquierda)

Fuente: SILVESTRI, G. Palacio de Correos. Proyecto Centro Cultural del Bicentenario. Memorias, ideas, futuro. Bs. As., Proyecto CCB, 2007 
Arquitectura pública: proyectos del Estado en la poscrisis argentina de 2001

En la escala urbana, la operación proyectual propone el despeje y reordenamiento del tránsito en el sector y la generación del Parque del Bicentenario que, en sentido norte-sur, permitirá una mejor perspectiva del palacio. Cabe notar que las incorporaciones internas de salas y terrazas no afectan la lectura urbana del palacio, que conserva sus fachadas intactas.

En ocasión de los festejos del Bicentenario en 2010 se inauguró la mansarda del cuerpo central que, con luz diurna, tiene una lectura similar a la original, pero por la noche admite un juego cromático y temático de luces que dan espectacularidad el edificio desafiando la severidad de la composición academicista (figura 3).

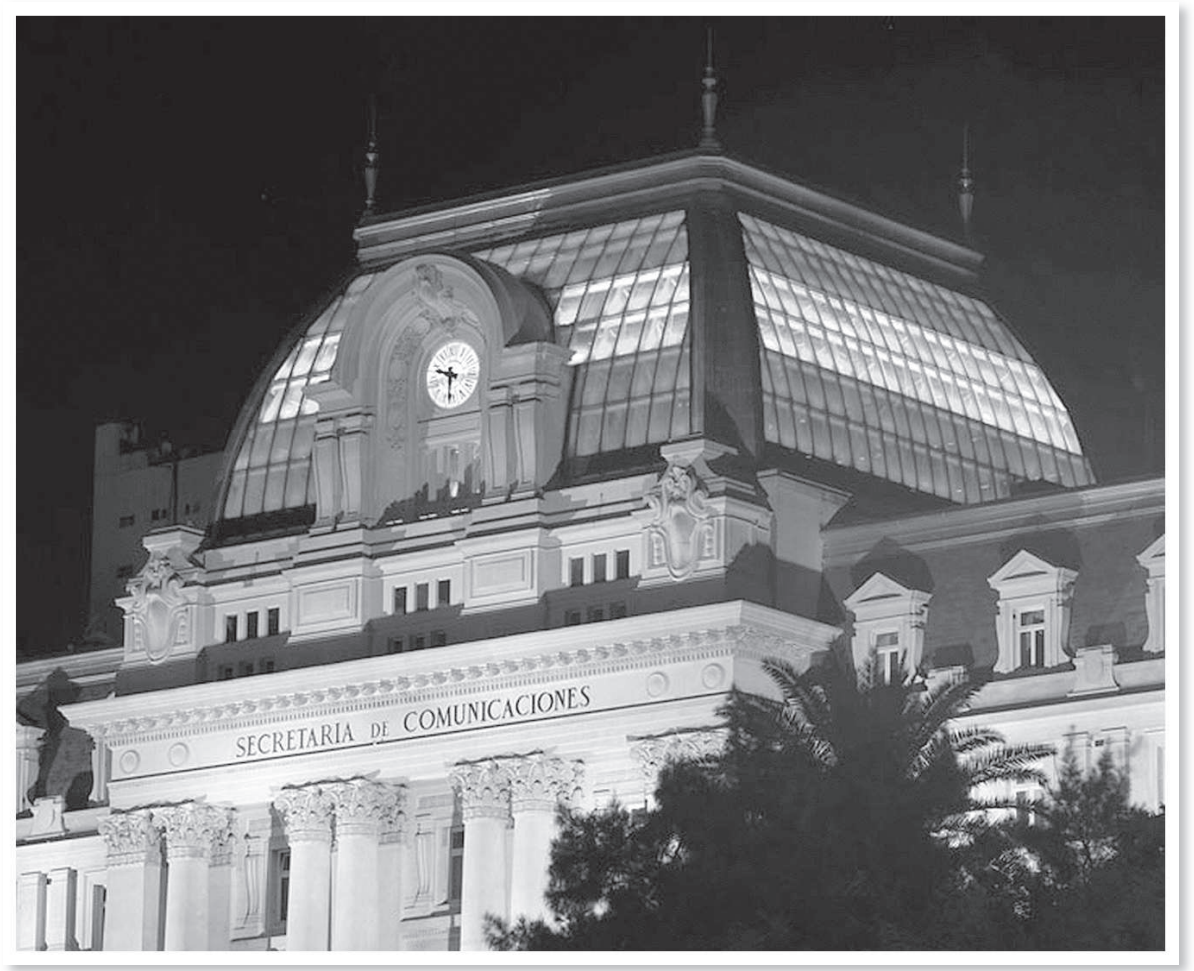

Figura 3. Intervención

en la mansarda Autores: B4FS, 2010.

Arqs. E. Bares, $F$.

Bares, $N$. Bares y

Daniel Becker con C

Ferrari y F. Schnack

Fuente: SILVESTRI,

G. Palacio de

Correos. Proyecto

Centro Cultural

del Bicentenario.

Memorias, ideas,

futuro. Bs. As.,

Proyecto CCB, 2007 


\section{Museo del Bicentenario Ex Aduana Taylor, CABA}

Es un espacio único que se dispone a espaldas de la Casa Rosada, sede del Poder Ejecutivo de la Nación. Forma parte del Parque del Bicentenario junto al Centro cultural en el palacio de correos. El edificio cubre los restos de la antigua Aduana Nueva, proyectada por el arquitecto inglés Edward Taylor en 1854 (primer concurso realizado en el país). Por entonces, el Río de la Plata llegaba hasta lo que actualmente es la Casa Rosada. Sobre este sitio, punto originario de la ciudad, se sucedieron un fuerte, la aduana y sucesivos edificios gubernamentales, para terminar la serie — verdadero palimpsesto— con el actual museo (figura 4).

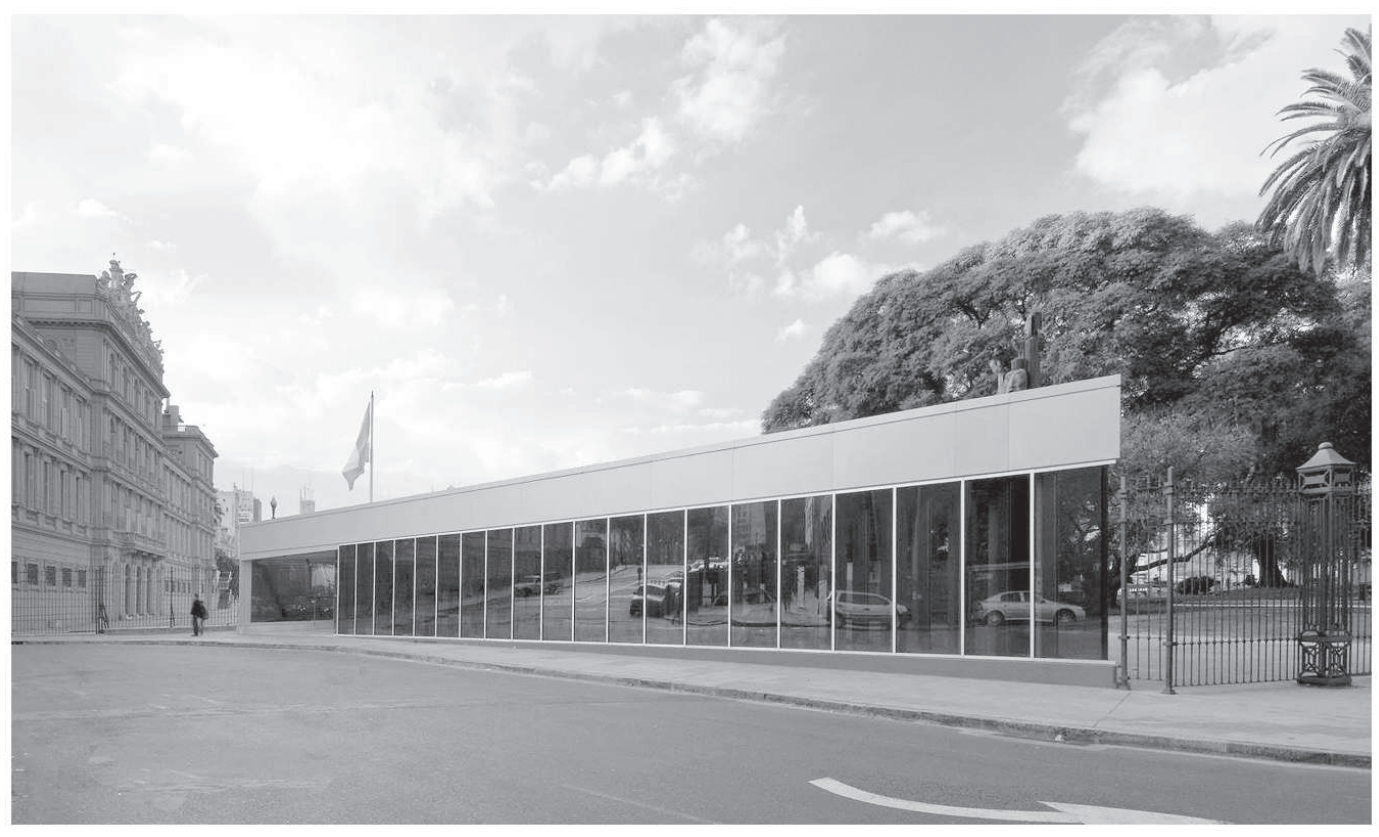

Figura 4. Acceso por el extremo sur

Autores: B4FS, 2010. Arqs. E. Bares, F. Bares, N. Bares y Daniel Becker con C. Ferrari y F. Schnack Fuente: GANDoLf, F. Proyecto Museo Aduana de Taylor. Bs. As. 2010 
Arquitectura pública: proyectos del Estado en la poscrisis argentina de 2001

De las antiguas construcciones se conservan restos de la galería abovedada de lo que fuera el Almacén de la Real Hacienda, del patio de maniobras y de la Aduana Nueva, todos a un nivel inferior a las calles circundantes. La Casa Rosada es adyacente a este conjunto. La operación consistió en la colocación de una cubierta acristalada sobre el patio de maniobras y un piso uniforme, que generó una espacialidad lineal apta para actos y encuentros protocolares. Bajo las bóvedas laterales se dispone la museografía (figura 5).

Exteriormente la cubierta es rasante al nivel de calle y se eleva en el extremo sur para permitir el ingreso. El diseño es muy elemental, con ritmos regulares dados por la carpintería de las aberturas y una cenefa que contiene el dispositivo estructural, consistente en vigas metálicas dispuestas muy próximas entre sí.

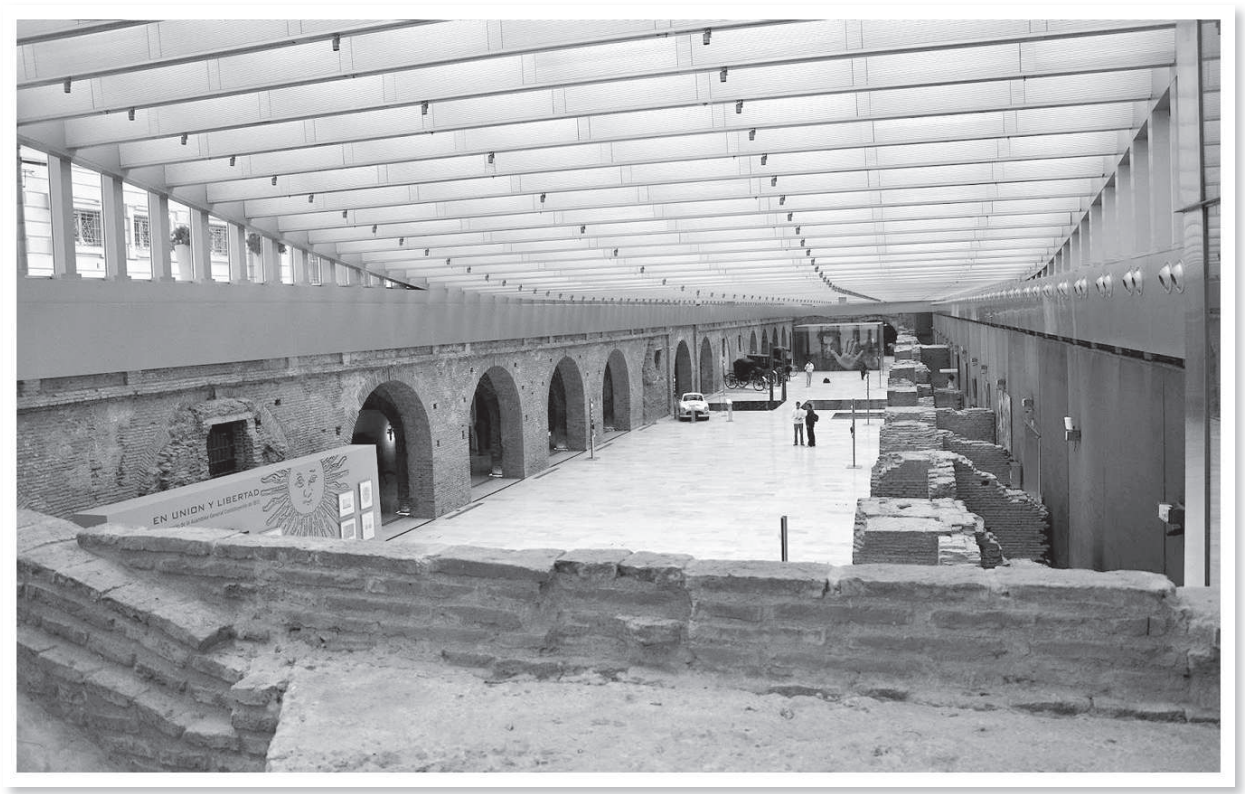

Figura 5. Interior

Fuente: sitio abierto en Internet. Accedido 06/02/2016 


\section{Centro Cívico Bicentenario, Córdoba}

La antigua ciudad de Córdoba es atravesada por el río Suquía, curso que en las últimas décadas ha sido objeto de revalorización paisajística. En el período de modernización de la ciudad, a lo largo del río se extendió el ferrocarril y se localizaron equipamientos industriales. Estos predios quedaron desafectados y se generaron áreas de vacancia con la particularidad de estar en proximidad con el centro de la ciudad. Por otra parte, la ciudad de Córdoba carecía de un centro de gobierno acorde con su jerarquía, por lo que desde varias décadas atrás se venía considerando la construcción de una nueva sede. Mediante una iniciativa privada correspondida por el gobierno, se dispuso la construcción del Centro Cívico del Bicentenario en los predios vacantes de ferrocarril Mitre, detrás de la respectiva estación de pasajeros. El autor de la obra es el Arq. Lucio Morini, junto con GGMPU Arquitectos. La pieza dominante es un prisma generado por la superposición de plantas cuadras que van rotando sobre un eje vertical, lo cual deviene en un volumen poliédrico irregular (figura 6).

La imagen dominante está dada por una envolvente de hormigón calado que se adapta al volumen resultante y otorga a la pieza una presencia diferenciada en el entorno abierto donde se localiza. Este edificio vertical contiene las oficinas gubernamentales; se completa con otro cuerpo bajo, horizontal, de planta recortada, destinado a salas de reuniones, auditorio, estacionamientos, etc. Sobre este edificio se ubica la casa del gobernador, rodeada de terrazas verdes.

El objeto es extraño en el paisaje cordobés. Si bien está convenientemente emplazado en el borde del área central, se presenta aislado y poco accesible, en contraste con la rica trama peatonal del centro cordobés. Se refuerza este aislamiento por el cerco de rejas, virtualmente infranqueable para el ciudadano, y la ubicación de la pieza más icónica sobre un espejo de agua que enfatiza su carácter hierático. El conjunto capta la atención del ciudadano, pero no provoca empatías ni logra hacerse reconocible como un edificio institucional. La prensa se ha hecho eco de las opiniones no siempre laudatorias de una obra que, tratando de afirmarse a través de una imagen arquitectónica innovadora, se ve amenazada por el desapego social. 
Arquitectura pública: proyectos del Estado en la poscrisis argentina de २००८

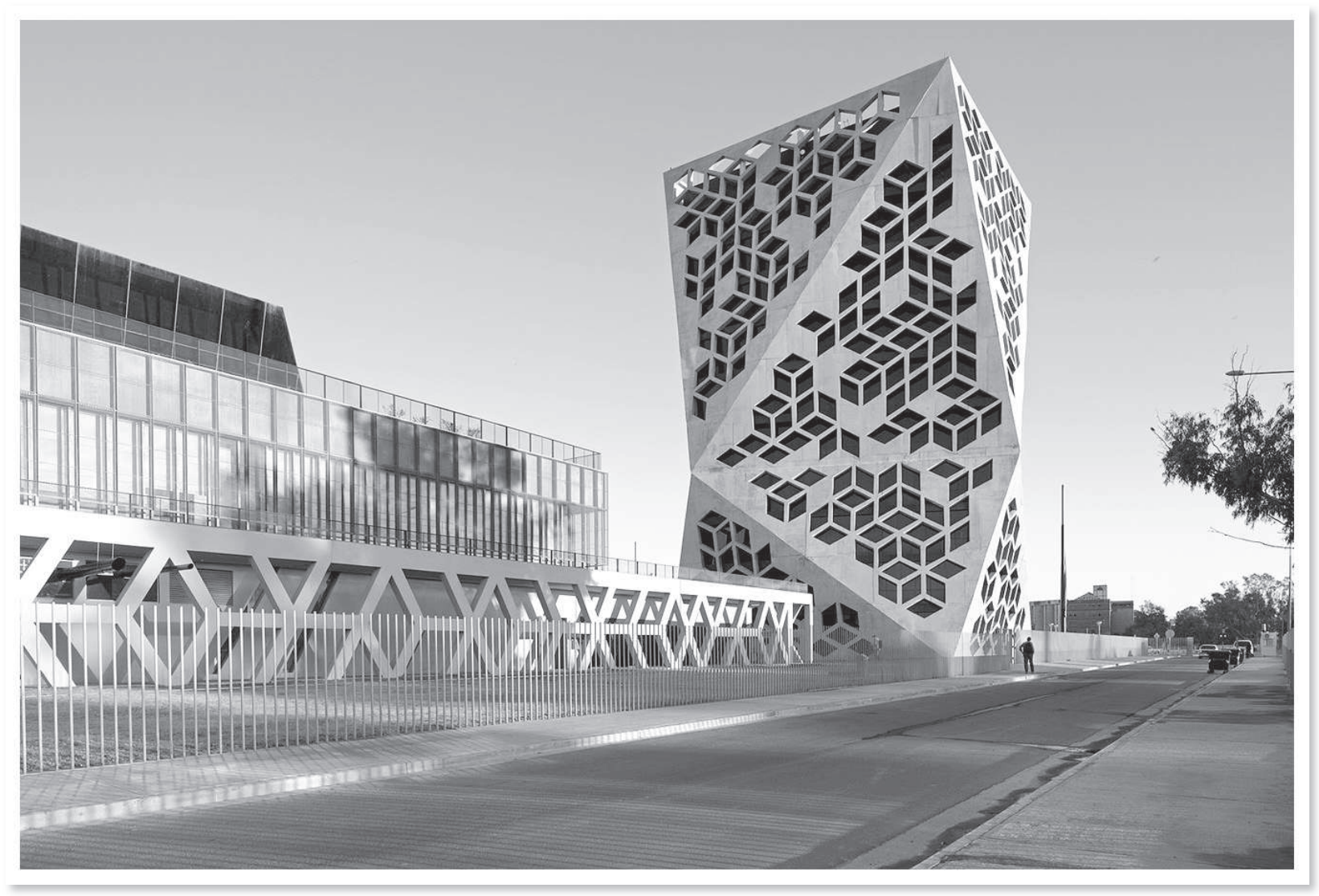

Figura 6. Envolventes caladas

Autores: Lucio Morini y GGMPU Arquitectos

Fuente: www.plataformaarquitectura.cl. Accedido 6/02/2016. Foto: Claudio Manzoni 


\section{Ciudad Judicial, Salta}

El nuevo centro judicial se ubica en la periferia de Salta, en un área de expansión de muy baja densidad residencial, vinculado con la ciudad central por una autopista. El complejo está próximo a otras sedes judiciales y de seguridad y a un pequeño centro comercial (que compensa su aislamiento) (figura 7).

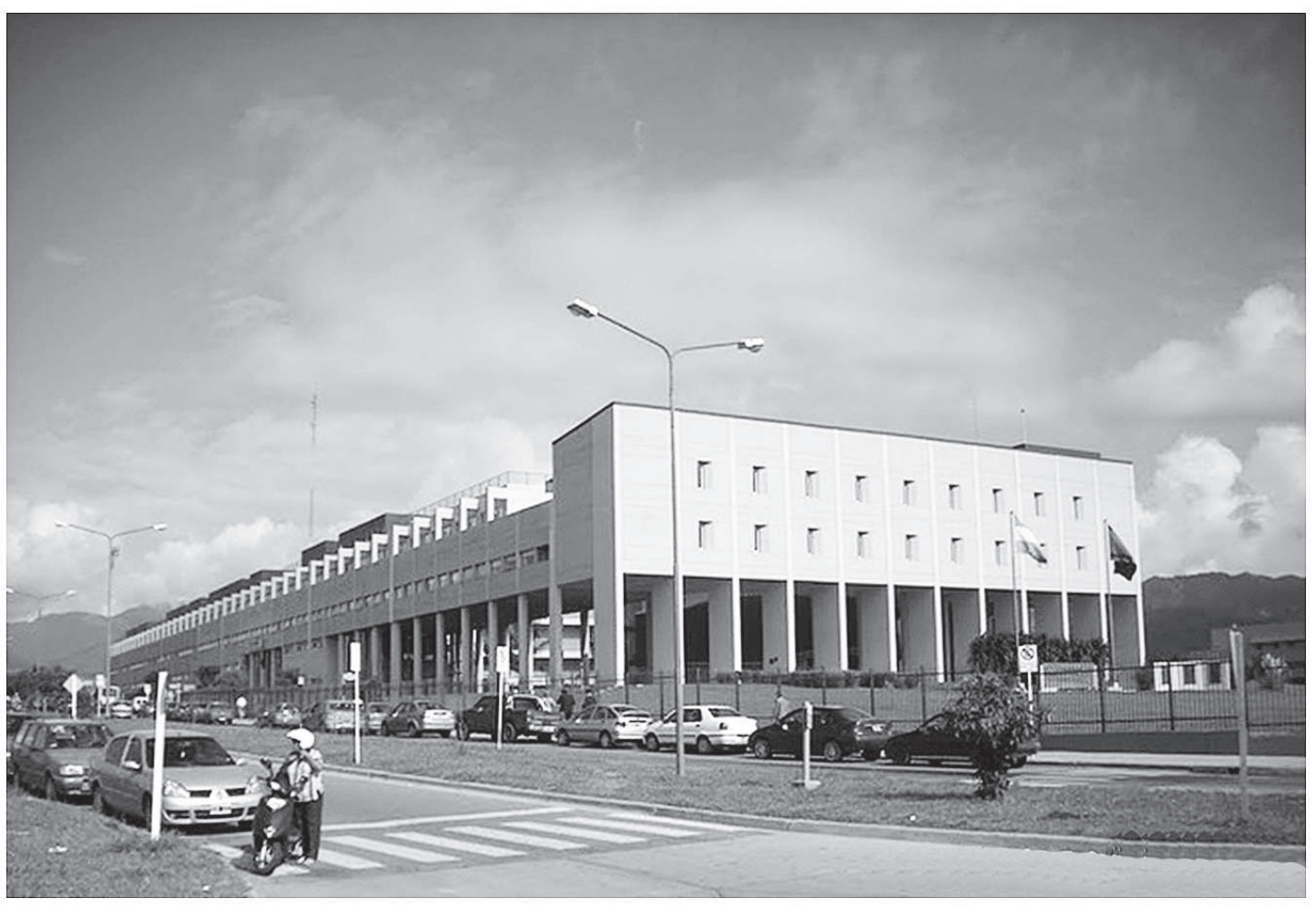

Figura 7. Emplazamiento suburbano de la obra

Autores: Arqs. Manuel Gálvez y Santiago Autunno. Concurso, 2004

Fuente: http://galvez-autunno.com/ 
Arquitectura pública: proyectos del Estado en la poscrisis argentina de 2001

El emplazamiento fuera de la ciudad tradicional, allende el anillo vial de circunvalación, acrecienta la percepción de una localización extramuros. Siendo Salta una ciudad antigua, poseedora de bello centro histórico y con trazados, parques y edilicias indicativos de una ciudad consolidada en el tiempo y arraigada en su historia, el desplazamiento hacia las afueras de un elemento tan significativo para el estado republicano como es la justicia solo encuentra una justificación práctica (disponibilidad de tierras, accesibilidad vial). Tal localización, como así también la estética basada en una arquitectura de macrobloques colocados en un vacío poco jerarquizado, poco contribuye a la necesidad de reforzar el valor de la justicia en el seno social y de la arquitectura como recurso capaz de contribuir a la construcción de lo simbólico.

\section{Parque y Centro Cívico Terrazas del Portezuelo, San Luis}

El complejo se ubica en la periferia de San Luis e incorpora al paisaje desértico un conjunto de formas que establecen una relación de figura-fondo con el paisaje. La más distintiva corresponde al cuerpo, que puede describirse como una pirámide trunca a la que a su vez se separó en partes. Estas secciones se ubican sobre una plataforma que las separa del terreno y aumenta su artificialidad. El complejo se integra con varios edificios destinados a los ministerios y servicios complementarios, estos últimos muy necesarios si se consideran las condiciones de aislamiento que implica el emplazamiento de la obra. En efecto, con el argumento de la descentralización de la ciudad se desplaza el principal conjunto cívico de la provincia a la periferia de la capital, accesible solo por medios automotores, y se logra un efecto de negación del valor de centralidad que históricamente han tenido los edificios gubernamentales.

Debido a su emplazamiento, el proyecto se debate entre los requerimientos funcionales derivados de una política de descentralización de dudosa necesidad (San Luis es una ciudad que no presenta congestión ni densidades que presupongan tal necesidad) y las formas gestuales y ampulosas mediante las cuales el proyectista pretende recuperar no solo una presencia monumental en el paisaje, sino también una dimensión simbólica de lo cívico mediante la excepcionalidad de la forma (figura 8). 


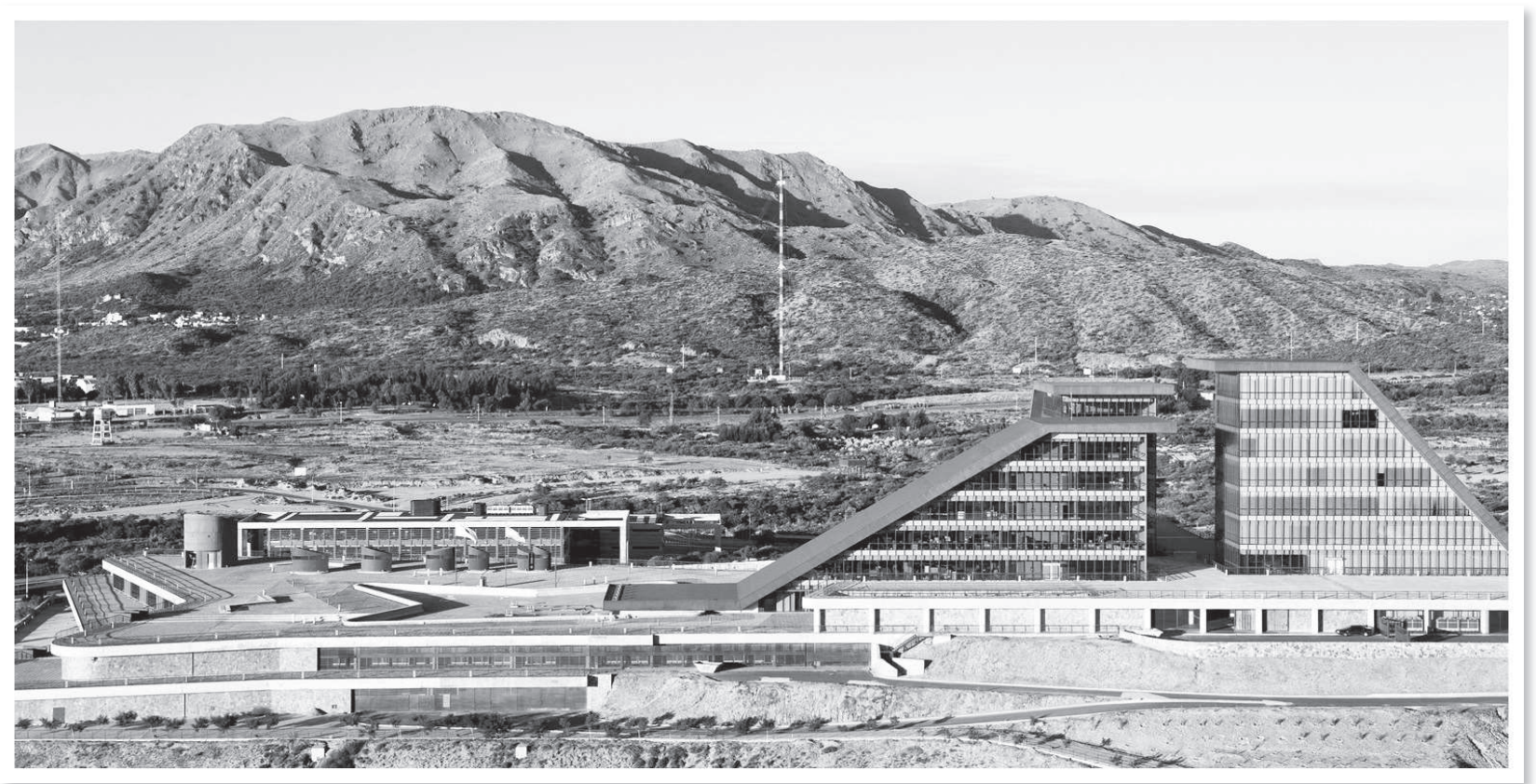

Figura 8. Enclave cívico en el paisaje

Autores: Arq. Esteban Bondone. Gobierno de San Luis, 2010

Fuente: www.puntoapartesanluis.com.ar

\section{Paseo y Fiesta del Bicentenario, CABA}

La avenida 9 de Julio de la capital del país se convirtió en una ciudadela destinada a la celebración del Bicentenario. Tomando como referencia visual el obelisco, se montó un eje cívico flanqueado por pabellones destinados a las veinticuatro provincias argentinas, uno a los argentinos en el extranjero (provincia N. ${ }^{\circ} 25$ ), los ministerios, como así también a estands de comidas regionales. A lo largo del eje se dispusieron en secuencia grandes escena- 
Arquitectura pública: proyectos del Estado en la poscrisis argentina de 2001

rios destinados a los más variados géneros musicales del país, en tanto que en el escenario central se realizaron presentaciones de los artistas más representativos. Junto con este gran paseo se realizaron varios desfiles cívicos, militares y de performances artísticas que tomaron como tema trece episodios centrales en la historia del país. Por unos días, la conflictiva sociedad argentina halló en los festejos del Bicentenario un clima de sosiego y celebración que, en lo artístico, alcanzó un alto nivel de producción y calidad. El emplazamiento en el corazón de Buenos Aires reforzó el carácter capitalino de la ciudad, que dispuso sus avenidas más emblemáticas como espacios de civilidad (figura 9).

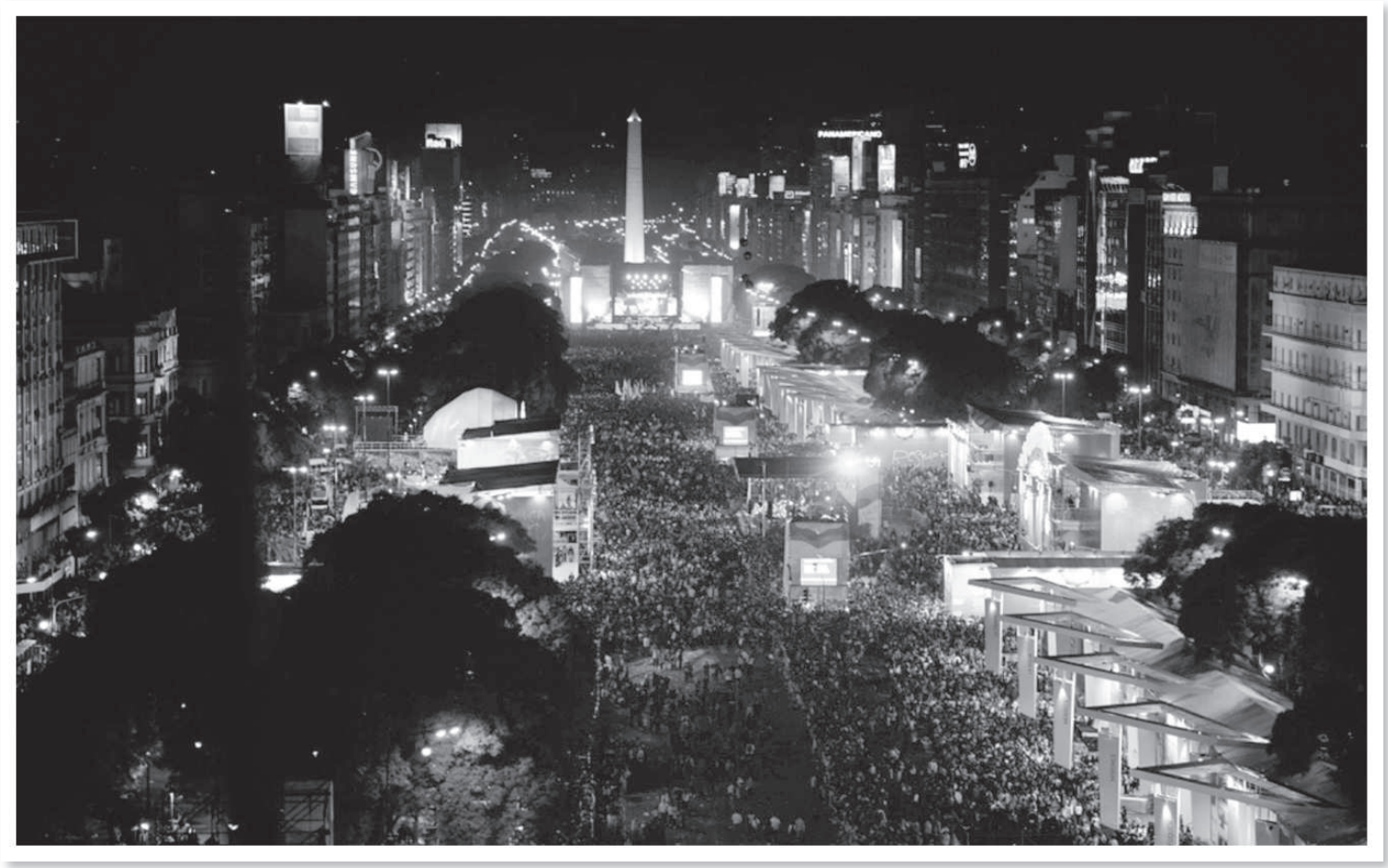

Figura 9. Vista general de la Av. 9 de Julio y pabellones de arquitectura efímera. Presidencia de la Nación, 2010 Fuente: http://rosiyseba.files.wordpress.com/010/05/23-arg.jpg 
Tecnópolis, Buenos Aires

Promocionada como la mayor megamuestra de ciencia, arte y tecnología del continente, es una feria que inicia sus actividades en 2010. Se ha constituido en el principal dispositi-

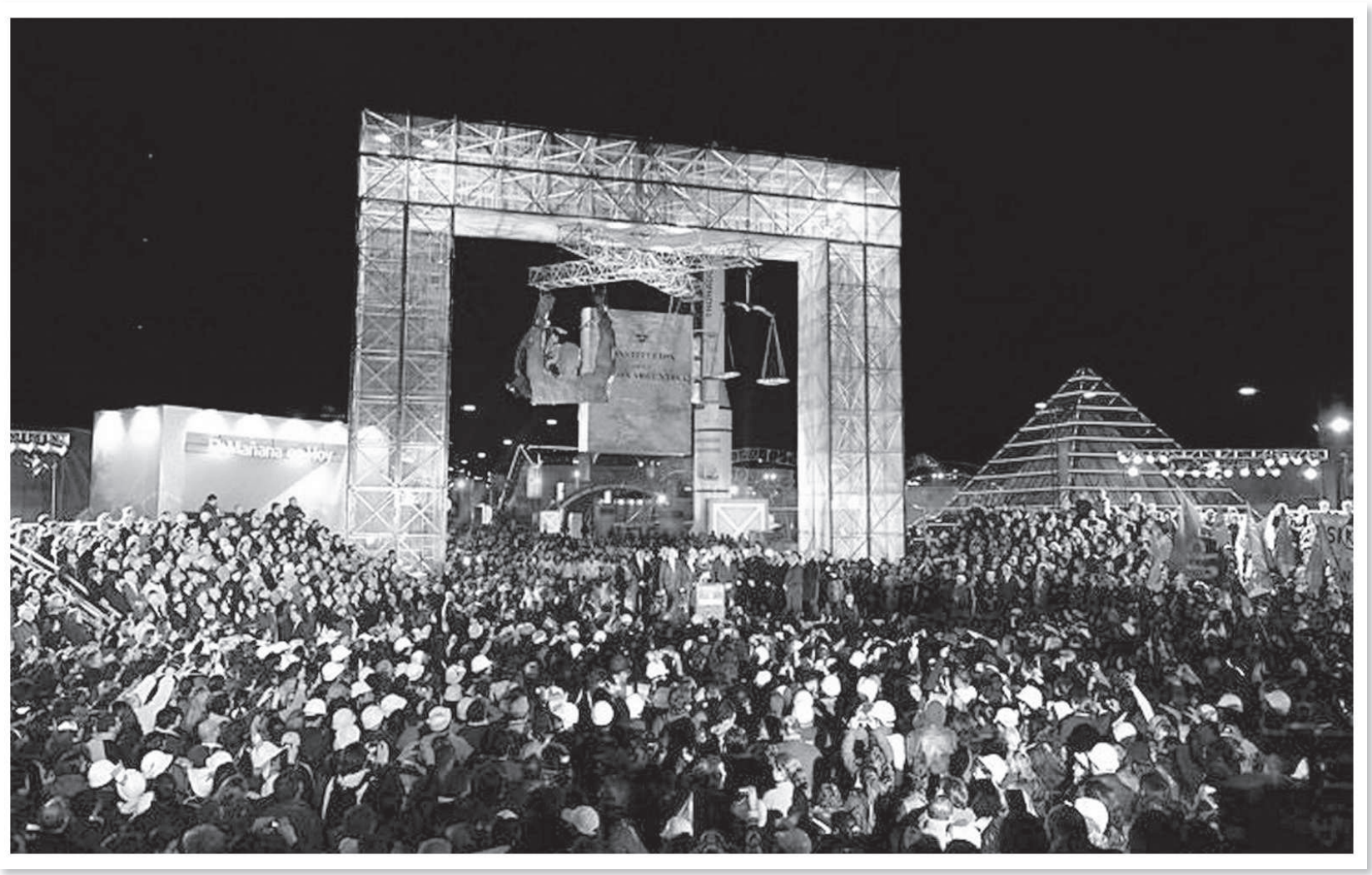

Figura 10. Portal del ingreso principal. Presidencia de la Nación. Tecnópolis Fuente: http://tecnopolis.ar/ 
vo propagandístico del Estado/gobierno kirchnerista, especialmente dedicado a un público escolar y familiar. Su primera edición fue en 2011, y se repite anualmente cada vez con distintos ejes temáticos. Está ubicada en predios fiscales del Estado nacional en Villa Martelli, sobre la avenida General Paz, avenida que deslinda el ejido de la CABA respecto de los municipios del Área Metropolitana de Buenos Aires. Formalmente la feria queda ubicada fuera de la capital federal pero inmediatamente sobre el límite; ello es así debido a que Mauricio Macri, por entonces jefe de Gobierno de la CABA, le negó al Poder Ejecutivo Nacional la autorización para el montaje de la feria en su jurisdicción argumentando motivos de funcionalidad urbana. Cabe suponer que fueron muy gravitantes en tal decisión las diferencias políticas que lo distanciaban del gobierno nacional, con lo cual el emplazamiento urbano dependió de una disputa territorial del poder. El gobierno actual continúa usando el predio, si bien con otro carácter (figura 10).

\section{Parque de la Memoria}

\section{Monumento a las Víctimas del Terrorismo de Estado, CABA}

El parque es un espacio público de la Ciudad de Buenos Aires ubicado sobre el Río de la Plata y adyacente a la Ciudad Universitaria. Su accesibilidad es casi exclusivamente vehicular, dada su ubicación en el borde fluvial, y además está condicionada por un régimen de uso con horarios establecidos de apertura y cierre. Se organiza como un amplio espacio verde con suave ondulación que avanza sobre el río conformando un amplio arco abierto al paisaje fluvial. El concepto es el de una hendidura en la colina - herida abierta-, a cuyos lados se extienden cuatro muros de disposición quebrada — estelas- que contienen los nombres de víctimas del terrorismo de Estado. Es posible agregar nuevos nombres en la medida en que se identifican más víctimas, tareas que continúan a más de treinta años de los hechos. El complejo incluye obras escultóricas, la sala PAyS (Presentes Ahora y Siempre) para actividades artísticas y culturales y un centro de información.

El parque es una iniciativa de Fernando de la Rúa cuando ejercía la jefatura de gobierno de la CABA; el proceso fue controvertido y polémico, siendo el proyecto resultado de un concurso convocado por la Facultad de Arquitectura, Diseño y Urbanismo de la Universidad de Buenos Aires (figura 11). 


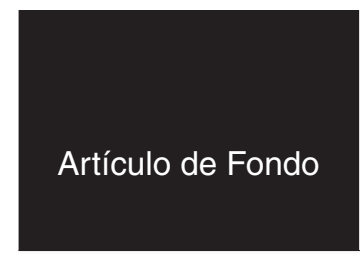

Julio Arroyo

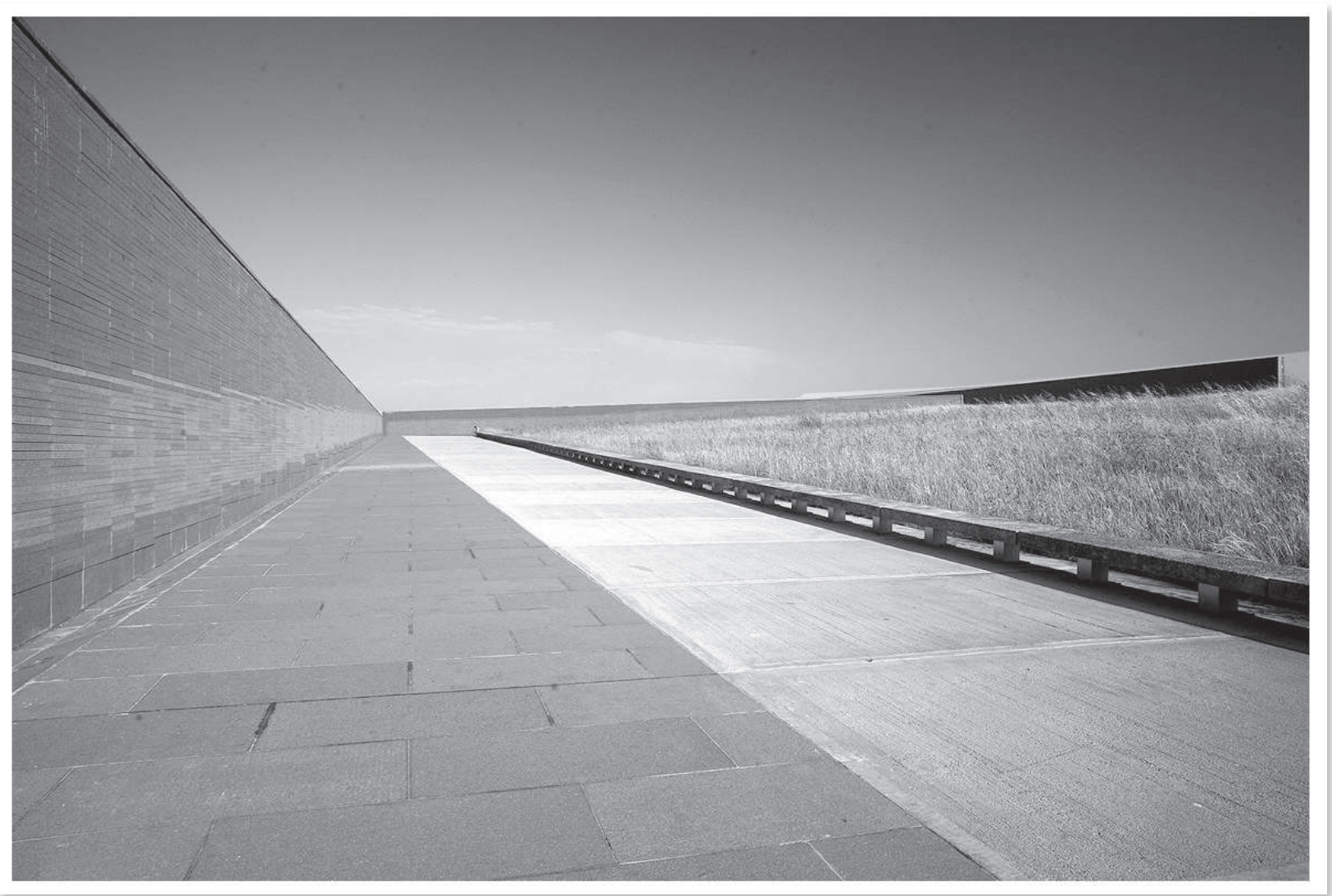

Figura 11. Estelas con los nombres de las víctimas

Autores: Estudio Baudizzone-Lestard-Varas. Arquitectos asociados C. Ferrari y D.

Becker. Municipalidad de la Ciudad Autónoma de Buenos Aires. Concurso, 2007

Fuente: http://www.revistaplot.com/ 


\section{Consideraciones}

Entre el edificio público y la ciudad escindida se da una relación ambigua. Allí donde el nuevo equipamiento supone un impacto en el ambiente, un efecto de forma en la imagen urbana del sector, una presencia activa del Estado y una oportunidad de consolidar un concepto de ciudadanía, la ciudad física, social y cultural se desagrega en procesos que enfatizan la disyunción y la eventualidad. A la certidumbre y concreción material que significa una obra nueva la confrontan las indeterminaciones de la ciudad escindida que deriva en procesos de discontinuidad, disfuncionalidad, obsolescencia o precariedad de la ciudad física, de anomia, exclusión y segregación de la social y de la relativización valorativa y dispersión narrativa de la cultural. El impacto de un nuevo equipamiento, independientemente de su función y escala, es relativo, y los casos relevados no alcanzan a establecer un patrón que permita comprender de manera conclusiva cómo es esta relación de la arquitectura con la ciudad.

A través de los casos presentados se hacen algunas consideraciones, relacionadas con lo siguiente: a) Emplazamiento urbano. Se trata de ponderar cómo impactan en la proposición proyectual y en la ocupación fáctica de los equipamientos las relaciones entre el sitio de localización y la ciudad en su conjunto. En la tabla 1 se relacionan condiciones de emplazamiento y tipo de equipamientos.

En general, estas obras se construyeron en los sitios posibles antes que convenientes, casi siempre condicionados por la disponibilidad de tierras fiscales antes que por una estrategia de emplazamientos. Pudiendo ser focos de una centralidad vigorosa no se resuelven como tales o bien no alcanzan el grado de intensidad que otra localización hubiese permitido.

La estrategia de utilizar nuevos equipamientos para reforzar o generar centralidad urbana ha sido explícita en el caso de Salta, en donde se propone agrupar un conjunto de equi- 


\section{Tabla l}

\begin{tabular}{|c|c|c|c|c|c|}
\hline $\begin{array}{l}\text { Emplazamiento } \\
\text { urbano }\end{array}$ & $\begin{array}{l}\text { Centro pre- } \\
\text { existente }\end{array}$ & $\begin{array}{l}\text { Nuevos } \\
\text { centros }\end{array}$ & $\begin{array}{l}\text { Áreas de } \\
\text { vacancia }\end{array}$ & $\begin{array}{l}\text { Bordes } \\
\text { urbanos }\end{array}$ & Otros \\
\hline Equipamiento & & & & & \\
\hline $\begin{array}{l}\text { Centro Cultural } \\
\text { del Bicentenario, CABA }\end{array}$ & & & & & \\
\hline $\begin{array}{l}\text { Museo del Bicentenario } \\
\text { ex Aduana Taylor, CABA }\end{array}$ & & & & & \\
\hline $\begin{array}{l}\text { Centro Cívico } \\
\text { del Bicentenario, Córdoba }\end{array}$ & & & & & \\
\hline $\begin{array}{l}\text { Ciudad Judicial, } \\
\text { Salta }\end{array}$ & & & & & \\
\hline $\begin{array}{l}\text { Parque y Centro Cívico } \\
\text { Terrazas del Portezuelo, San Luis }\end{array}$ & & & & & \\
\hline $\begin{array}{l}\text { Paseo y Fiesta } \\
\text { del Bicentenario, CABA }\end{array}$ & & & & & \\
\hline $\begin{array}{l}\text { Tecnópolis, } \\
\text { CABA }\end{array}$ & & & & & \\
\hline $\begin{array}{l}\text { Parque de la Memoria. } \\
\text { Monumento a las Víctimas } \\
\text { del Terrorismo de Estado, CABA }\end{array}$ & & & & & \\
\hline \multicolumn{6}{|c|}{$\begin{array}{r}\text { Referencias: } \\
\text { celda grisada } \\
\text { señala opción de } \\
\text { emplazamiento } \\
\text { urbano }\end{array}$} \\
\hline
\end{tabular}


pamientos heterogéneos que abarca, además de la sede judicial, una cárcel, un centro comercial y campus universitarios. El otro caso es el de San Luis. Si bien en ambos existe la intención de generar nueva centralidad, esta se desvirtúa al ser resuelta como un conjunto o enclave urbano desmembrado de la trama topológica de la ciudad histórica. Ambos complejos se ubican en bordes urbanos y tienen como principal conexión con la ciudad central la vial.

La ocupación de áreas de vacancia, originadas en suelo urbano que ha perdido los usos originales, es siempre una oportunidad urbanística, puesto que se trata de localizaciones con fuerte involucramiento con todas las dimensiones de la ciudad (buenas localización relativa, disponibilidad de infraestructura, elementos patrimoniales, memoria ciudadana por las actividades del pasado, etc.). Esta situación es verificable en el Centro Cívico de Córdoba, emplazado al lado del río Suquía, entre el centro de la ciudad y uno de los llamados barrio-pueblo más característicos: el Gral. Paz. Tiene un alto potencial de constituirse en un articulador urbano invirtiendo la condición de duro borde interior ferroviaria que caracterizaba al sector.

La mejor explotación de una situación de borde urbano se da en el Parque de la Memoria, en donde se hace un aprovechamiento pleno del potencial paisajístico del Río de la Plata.

Las dos obras más representativas del período, el Centro Cultural y el Museo del Bicentenario, participan de centros preexistes. En el primer caso, por ser una re-funcionalización de un edificio que ya constituía un foco de centralidad: el antiguo Palacio de Correos, ahora recuperado; en el segundo, por ser una intervención sobre un sitio arqueológico adyacente a otro elemento primario: la Casa Rosada. En tal sentido, las intervenciones no tuvieron otro impacto que el de reforzar una estructura urbana ya consolidada, lo cual en cierto modo constituye una oportunidad perdida de generar nueva centralidad con obras de tan alto costo. Como ejemplo de localizaciones meramente prácticas, sea por disponibilidad de tierra fiscal o por disputas de jurisdicciones políticas, como es el caso de Tecnópolis o de Córdoba.

b) Implantación. En la tabla 2 se analiza el modo en que inciden, en la proposición proyectual y en la ocupación efectiva, la relación del equipamiento con su entorno inmediato ponderado a través variables e indicadores determinados. 


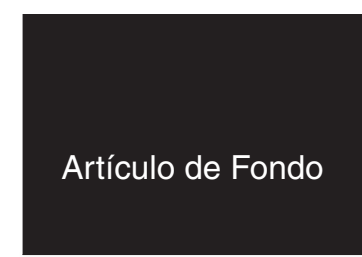

Julio Arroyo

\section{Tabla 2}

\begin{tabular}{|c|c|c|c|c|c|c|c|}
\hline Variables de diseño & $\begin{array}{l}\text { Imagen } \\
\text { urbana }\end{array}$ & Visuales & Escala & Bordes & $\begin{array}{l}\text { Tipo- } \\
\text { logía } \\
\text { edilicia }\end{array}$ & $\begin{array}{l}\text { Espacio } \\
\text { cedido } \\
\text { al uso } \\
\text { público }\end{array}$ & Gestión \\
\hline Indicadores & $\begin{array}{l}\text { Institucional } \\
\text { / Doméstica } \\
\text { / Mediática } \\
\text { Icónica / } \\
\text { simbólica / } \\
\text { Indicial }\end{array}$ & $\begin{array}{l}\text { Conexión } \\
\text { visual hacia y } \\
\text { desde el equi- } \\
\text { pamiento: } \\
\text { Aprovechadas } \\
\text { / Ignoradas / } \\
\text { por defecto }\end{array}$ & $\begin{array}{l}\text { Ruptura / } \\
\text { integración } \\
\text { con entorno } \\
\text { / indefinida }\end{array}$ & $\begin{array}{l}\text { Límites concre- } \\
\text { tos / virtuales } \\
\text { Accesibilidad } \\
\text { física / visual } \\
\text { Entorno propio } \\
\text { / entorno } \\
\text { urbano }\end{array}$ & $\begin{array}{l}\text { Exenta / } \\
\text { contacto } \\
\text { Patio / planta } \\
\text { central - Radial } \\
\text {-Lineal -axial - } \\
\text { red - etc. } \\
\text { Tensiones }\end{array}$ & $\begin{array}{l}\text { Explanadas } \\
\text { Jardines } \\
\text { Veredas } \\
\text { Terrazas } \\
\text { Miradores } \\
\text { Balcones } \\
\text { Expansiones }\end{array}$ & $\begin{array}{l}\text { Facilitadora } \\
\text { / negadora } \\
\text { del uso } \\
\text { público } \\
\text { programado } \\
\text { / eventual }\end{array}$ \\
\hline \multicolumn{8}{|l|}{ Equipamiento } \\
\hline $\begin{array}{l}\text { Centro Cultural } \\
\text { del Bicentenario, CABA }\end{array}$ & & $\begin{array}{l}\text { Cúpula, espe- } \\
\text { cialmente por } \\
\text { iluminación } \\
\text { nocturna. }\end{array}$ & & $\begin{array}{l}\text { Puesta en valor } \\
\text { del entorno } \\
\text { propio. }\end{array}$ & $\begin{array}{l}\text { Preservación } \\
\text { de las carac- } \\
\text { terísticas } \\
\text { tipológicas } \\
\text { en el sector } \\
\text { palaciego. }\end{array}$ & Por defecto & $\begin{array}{l}\text { Las políticas } \\
\text { de gestión } \\
\text { varían con los } \\
\text { períodos de } \\
\text { gobierno. }\end{array}$ \\
\hline $\begin{array}{l}\text { Museo del Bicentenario } \\
\text { ex Aduana Taylor, CABA }\end{array}$ & $\begin{array}{l}\text { Procura } \\
\text { una imagen } \\
\text { por efecto } \\
\text { de mínima } \\
\text { presencia. }\end{array}$ & $\begin{array}{l}\text { Se comunica } \\
\text { visualmente } \\
\text { con Casa } \\
\text { Rosada. }\end{array}$ & $\begin{array}{l}\text { Procura } \\
\text { integración } \\
\text { sin protago- } \\
\text { nismo. }\end{array}$ & $\begin{array}{l}\text { No establece } \\
\text { relación con } \\
\text { el espacio } \\
\text { verde público } \\
\text { adyacente. }\end{array}$ & Sin relevancia. & No previsto. & $\begin{array}{l}\text { Las políticas } \\
\text { de gestión } \\
\text { varían con } \\
\text { los períodos } \\
\text { de gobierno. }\end{array}$ \\
\hline $\begin{array}{l}\text { Centro Cívico del } \\
\text { Bicentenario, Córdoba }\end{array}$ & $\begin{array}{l}\text { Procura } \\
\text { generar un } \\
\text { ícono. }\end{array}$ & Por defecto. & $\begin{array}{l}\text { No propone } \\
\text { relaciones } \\
\text { más allá de } \\
\text { las propias } \\
\text { por defecto. }\end{array}$ & $\begin{array}{l}\text { Cercado } \\
\text { perimetral. } \\
\text { Acceso } \\
\text { restringido. }\end{array}$ & Sin relevancia. & $\begin{array}{l}\text { Niega usos } \\
\text { eventuales. }\end{array}$ & \\
\hline $\begin{array}{l}\text { Ciudad Judicial, } \\
\text { Salta }\end{array}$ & Por defecto. & Por defecto. & Por defecto. & $\begin{array}{l}\text { Mínima } \\
\text { relación con } \\
\text { el entorno. }\end{array}$ & Patio central. & $\begin{array}{l}\text { La localización } \\
\text { frente a vías } \\
\text { de tránsito } \\
\text { rápido impide } \\
\text { buen uso de } \\
\text { exteriores. }\end{array}$ & \\
\hline $\begin{array}{l}\text { Parque y Centro Cívico } \\
\text { Terrazas del Portezuelo, } \\
\text { San Luis }\end{array}$ & $\begin{array}{l}\text { Procura } \\
\text { generar un } \\
\text { icono. }\end{array}$ & $\begin{array}{l}\text { Procura co- } \\
\text { nexión visual } \\
\text { hacia y desde } \\
\text { el equipa- } \\
\text { miento. }\end{array}$ & $\begin{array}{l}\text { Adecuada } \\
\text { al emplaza- } \\
\text { miento. }\end{array}$ & $\begin{array}{l}\text { Procura } \\
\text { articulaciones, } \\
\text { pero el empla- } \\
\text { zamiento no } \\
\text { favorece. }\end{array}$ & $\begin{array}{l}\text { Criterio de } \\
\text { distribución } \\
\text { generando } \\
\text { tensiones. }\end{array}$ & $\begin{array}{l}\text { Se propone } \\
\text { como un } \\
\text { parque. }\end{array}$ & \\
\hline
\end{tabular}


Arquitectura pública: proyectos del Estado en la poscrisis argentina de २००८

\section{Tabla 2}

\begin{tabular}{|c|c|c|c|c|c|c|c|}
\hline Variables de diseño & $\begin{array}{l}\text { Imagen } \\
\text { urbana }\end{array}$ & Visuales & Escala & Bordes & $\begin{array}{l}\text { Tipo- } \\
\text { logía } \\
\text { edilicia }\end{array}$ & $\begin{array}{l}\text { Espacio } \\
\text { cedido } \\
\text { al uso } \\
\text { público }\end{array}$ & Gestión \\
\hline Indicadores & $\begin{array}{l}\text { Institucional } \\
\text { / Doméstica } \\
\text { / Mediática } \\
\text { Icónica / } \\
\text { simbólica / } \\
\text { Indicial }\end{array}$ & $\begin{array}{l}\text { Conexión } \\
\text { visual hacia y } \\
\text { desde el equi- } \\
\text { pamiento: } \\
\text { Aprovechadas } \\
\text { / Ignoradas / } \\
\text { por defecto }\end{array}$ & $\begin{array}{l}\text { Ruptura / } \\
\text { integración } \\
\text { con entorno } \\
\text { / indefinida }\end{array}$ & $\begin{array}{l}\text { Límites concre- } \\
\text { tos / virtuales } \\
\text { Accesibilidad } \\
\text { física / visual } \\
\text { Entorno propio } \\
\text { / entorno } \\
\text { urbano }\end{array}$ & $\begin{array}{l}\text { Exenta / } \\
\text { contacto } \\
\text { Patio / planta } \\
\text { central - Radial } \\
\text {-Lineal -axial - } \\
\text { red - etc. } \\
\text { Tensiones }\end{array}$ & $\begin{array}{l}\text { Explanadas } \\
\text { Jardines } \\
\text { Veredas } \\
\text { Terrazas } \\
\text { Miradores } \\
\text { Balcones } \\
\text { Expansiones }\end{array}$ & $\begin{array}{l}\text { Facilitadora } \\
\text { / negadora } \\
\text { del uso } \\
\text { público } \\
\text { programado } \\
\text { / eventual }\end{array}$ \\
\hline \multicolumn{8}{|l|}{ Equipamiento } \\
\hline $\begin{array}{l}\text { Paseo y Fiesta } \\
\text { del Bicentenario, CABA }\end{array}$ & $\begin{array}{l}\text { Imagen } \\
\text { mediática. }\end{array}$ & $\begin{array}{l}\text { Genera } \\
\text { entorno } \\
\text { propio con } \\
\text { multifocal. }\end{array}$ & $\begin{array}{l}\text { Adecuada } \\
\text { al emplaza- } \\
\text { miento. }\end{array}$ & & $\begin{array}{l}\text { Estructura } \\
\text { lineal-axial. }\end{array}$ & $\begin{array}{l}\text { Se propone } \\
\text { como un } \\
\text { paseo. }\end{array}$ & $\begin{array}{l}\text { Plena } \\
\text { accesibilidad } \\
\text { pública. }\end{array}$ \\
\hline $\begin{array}{l}\text { Tecnópolis, } \\
\text { CABA }\end{array}$ & $\begin{array}{l}\text { Imagen } \\
\text { mediática. }\end{array}$ & $\begin{array}{l}\text { Genera } \\
\text { entorno } \\
\text { propio. }\end{array}$ & $\begin{array}{l}\text { Poco } \\
\text { atendido. } \\
\text { Elementos } \\
\text { diversos. }\end{array}$ & $\begin{array}{l}\text { Cercado } \\
\text { perimetral. } \\
\text { Acceso } \\
\text { controlado. }\end{array}$ & $\begin{array}{l}\text { Estructura } \\
\text { en grilla. }\end{array}$ & $\begin{array}{l}\text { Se propone } \\
\text { como una } \\
\text { feria. }\end{array}$ & $\begin{array}{l}\text { Plena } \\
\text { accesibilidad } \\
\text { pública. }\end{array}$ \\
\hline $\begin{array}{l}\text { Parque de la Memoria. } \\
\text { Monumento a las } \\
\text { Víctimas del Terrorismo } \\
\text { de Estado, Caba }\end{array}$ & $\begin{array}{l}\text { Imagen } \\
\text { paisajística } \\
\text { fuerte-- } \\
\text { mente } \\
\text { simbólica. }\end{array}$ & $\begin{array}{l}\text { Genera y } \\
\text { potencia } \\
\text { conexiones } \\
\text { visuales con } \\
\text { el río y la } \\
\text { ciudad. }\end{array}$ & $\begin{array}{l}\text { Adecuada } \\
\text { al emplaza- } \\
\text { miento. }\end{array}$ & $\begin{array}{l}\text { Cercado } \\
\text { perimetral. } \\
\text { Acceso } \\
\text { controlado. }\end{array}$ & $\begin{array}{l}\text { Estructura } \\
\text { por focos } \\
\text { que generan } \\
\text { tensiones y } \\
\text { recorridos. }\end{array}$ & $\begin{array}{l}\text { Se propone } \\
\text { como un } \\
\text { parque. }\end{array}$ & $\begin{array}{l}\text { Plena } \\
\text { accesibilidad } \\
\text { pública. }\end{array}$ \\
\hline
\end{tabular}

Referencias: A Incidencia intencional evaluada como no favorable.

A Incidencia intencional evaluada como favorable.

A Incidencia por defecto o no intencional.

Incidencia neutra o no evaluable. 
La mayoría de los equipamientos genera una imagen y escala institucional si por tal se entiende un complejo perceptivo/cognitivo que le permite al sujeto diferenciar el carácter de equipamiento respecto de la edilicia residencial, comercial, de la producción, etc. La forma de de generar la imagen o presencia urbana varía entre la intencionalidad fuertemente icónica del Centro Cívico de Córdoba o San Luis, la indiciaria del Museo del Bicentenario, la institucional del Centro Cultural del Bicentenarios y la mediática de Tecnópolis y, en su momento, del Paseo y fiesta de Bicentenario, que apelaron a recursos visuales de los medios de comunicación visual antes que a los propiamente arquitectónicos.

En general las visuales hacia el nuevo equipamiento han sido deliberadamente atendidas en el caso de Córdoba, San Luis, Salta y Tecnópolis, lo cual guarda relación con el interés icónico y mediático, según los casos, que demandan un fuerte estímulo de la visualidad. Esto se logra por formalizaciones atípicas, inclusión de elementos dinámicos, emisión lumínica o incorporación de cartelería dinámica. Las relaciones escalares con el entorno no han sido trabajadas de manera explícita; en general se aprecia que las relaciones se establecen por defecto, sin intencionalidad, excepto en el caso de Terrazas del Portezuelo, en donde se ha procurado un efecto de impacto escalar en el paisaje abierto de la periferia de San Luis.

Una observación aparte es para el Centro Cultural, la obra de mayor valor propagandístico del período que, excepto por el cambio de materialidad de la mansarda central, no ha alterado su imagen, aun siendo que en interior se despliega un rico juego de formas que quedan contenidas en la matriz tipológica del edificio palaciego, lo que constituye una verdadera oportunidad perdida de haber generado un nuevo centro con un mayor impacto de forma de haberse optado por una intervención en otro sitio.

Los límites se materializan con cercos y enrejados ostensibles en el Memorial, Tecnópolis, Córdoba y San Luis, aunque se preserva la permeabilidad visual. El acceso físico es controlado o restringido en casi todos los casos, en ocasiones de manera síc, como en Córdoba. Se diferencia el caso del Palacio de Correos por ser un edificio de fachadas consolidadas, por lo que no es aplicable este indicador.

Excepto el Museo del Bicentenario, los casos restantes son todos cuerpos exentos que generan entornos propios. Llama la atención que solo en San Luis y en el parque memorial 
se multiplican los espacios librados al uso público espontáneo, como explanadas, jardines, miradores, etc. Un caso aparte lo constituye en Centro Cultural, que ha generado terrazas y un espacio totalmente excepcional, la mansarda central, como miradores urbanos. La administración de estos equipamientos no siempre atiende a la voluntad de los proyectistas de generar espacios de libre ocupación, por lo que se imponen restricciones en la mayoría de los casos mediante distintas modalidades: imposición de horarios, de controles, accesos restringidos, etc.

c) Forma. Se detectan los paradigmas dominantes (lo cual significa que no son excluyentes, pero sí prioritarios) que validan la forma y resultado de un proceso heurístico y como objeto de percepción plástica, uso práctico, experimentación espacial y adecuación ambiental. La tabla 3 muestra relaciones entre paradigma, variables e indicadores de diseño para los distintos casos.

El paradigma eco-ambiental incorpora a la arquitectura la atención de los procesos críticos del ambiente como ecosistema que preservar. Ha dado lugar a un importante desarrollo teórico que solo ha sido aplicado con relativa consistencia en el caso de San Luis. Está presente como aprovechamiento del paisaje en el parque memorial y como discurso pedagógico en Tecnópolis.

El paradigma autoral destaca los rasgos subjetivos del o los proyectistas en tanto cultores de formas asociadas a exploraciones o intereses personales, lo cual se hace más evidente en Córdoba, detrás de la figura de Lucio Morini. También se activa cuando la forma es resultado de un proceso heurístico, bien desarrollado por el proyectista, del que resulta un objeto pregnante, como es el caso de San Luis. Las soluciones divergentes para programas afines son indicativas de las búsquedas en las que están embarcados los autores y de cómo estas encomiendas se constituyen en oportunidades de innovación formal. Algo similar podría referirse del Centro Judicial de Salta, pero allí los arquitectos han procurado una respuesta tipológica y ajustada a los requerimientos funcionales antes que a exploraciones formales.

El informático-comunicacional enfatiza la aplicación de recursos computacionales y de las comunicaciones audiovisuales. Ello se manifiesta en la generación de la envolvente del centro cívico cordobés como un despliegue de una lámina de diseño paramétrico o en la aplicación de recursos de emisión o proyección de datos bajo la forma de animaciones, mappings, 
Julio Arroyo

\section{Tabla 3}

\begin{tabular}{|c|c|c|c|c|c|c|c|c|c|}
\hline Paradigma & ECO-AMBIENTAL & AUTORAL & $\begin{array}{c}\text { SEMIO- } \\
\text { LINGǗSTICO }\end{array}$ & $\begin{array}{l}\text { INFORMÁTICO- } \\
\text { MEDIÁTICOO }\end{array}$ & $\begin{array}{l}\text { PATRIMO- } \\
\text { NIAL }\end{array}$ & OBJETUAL & $\begin{array}{l}\text { FUNCIONAL- } \\
\text { OPERATIVO }\end{array}$ & $\begin{array}{l}\text { PRAGMÁTICO- } \\
\text { PRODUCTIVISTA }\end{array}$ & TIPOLÓGICO \\
\hline $\begin{array}{l}\text { Variables } \\
\text { de diseño }\end{array}$ & Sostenibilidad & $\begin{array}{c}\text { Subjetividad } \\
\text { autoral }\end{array}$ & $\begin{array}{l}\text { Índice, } \\
\text { íconos } \\
\text { símbolos } \\
\text { Sintaxis, } \\
\text { pragmática y } \\
\text { semántica }\end{array}$ & $\begin{array}{l}\text { Informática } \\
\text { TICs }\end{array}$ & $\begin{array}{l}\text { Historia } \\
\text { Memoria } \\
\text { Paisaje }\end{array}$ & $\begin{array}{l}\text { Materialidad } \\
\text { pesada } \\
\text { Materialidadad } \\
\text { liviana }\end{array}$ & $\begin{array}{l}\text { Subjetividad } \\
\text { colectiva }\end{array}$ & $\begin{array}{c}\text { Costo / } \\
\text { beneficio } \\
\text { Concreción }\end{array}$ & $\begin{array}{l}\text { Tipo edilicio } \\
\text { Tipo } \\
\text { funcional }\end{array}$ \\
\hline Indicadores & $\begin{array}{l}\text { Diseño biocli- } \\
\text { mático. } \\
\text { Acondiciona- } \\
\text { miento pasivo. } \\
\text { Certificaciones } \\
\text { de rendimiento } \\
\text { y eficiencia. } \\
\text { Aprovechamien- } \\
\text { to de recursos } \\
\text { paisajisticos. }\end{array}$ & $\begin{array}{l}\text { Expresionis- } \\
\text { mo / ges- } \\
\text { tualidadad I } \\
\text { exploración } \\
\text { morfolóó- } \\
\text { gica I I } \\
\text { Proyectista } \\
\text { con alto } \\
\text { grado de } \\
\text { exposición } \\
\text { mediátical I } \\
\text { académical } \\
\text { periodística. }\end{array}$ & $\begin{array}{l}\text { Neo- } \\
\text { moderno, } \\
\text { minima-- } \\
\text { lista, ver- } \\
\text { naculista, } \\
\text { High-tech. } \\
\text { eco-arqui- } \\
\text { tectura, } \\
\text { etc. } \\
\text { Metáforas / } \\
\text { narrativas. }\end{array}$ & $\begin{array}{l}\text { NURBS } \\
\text { Opera- } \\
\text { ciones } \\
\text { booleanas. } \\
\text { Parametris- } \\
\text { mo. } \\
\text { BIM. } \\
\text { Inclusión de } \\
\text { emisio- } \\
\text { nes (luz, } \\
\text { imagen, } \\
\text { sonido). }\end{array}$ & $\begin{array}{l}\text { Preserva- } \\
\text { ción / Res- } \\
\text { tauración / } \\
\text { Rehabi- } \\
\text { litación / } \\
\text { Puesta en } \\
\text { valor de: } \\
\text { Edificios / } \\
\text { Ambientes } \\
\text { / Paisajes / } \\
\text { Elementos } \\
\text { intangibles. }\end{array}$ & $\begin{array}{l}\text { Nuevos } \\
\text { materiales y } \\
\text { tecnologías. } \\
\text { Nuevos usos } \\
\text { de materia- } \\
\text { les y técnicas } \\
\text { tradicionales } \\
\text { Levedad / } \\
\text { inmateriali- } \\
\text { dad / trans- } \\
\text { parencia / } \\
\text { desapari- } \\
\text { ción/ tran- } \\
\text { sitoriedad / } \\
\text { disolución. } \\
\text { Vegetación. }\end{array}$ & $\begin{array}{l}\text { Participacio- } \\
\text { nismo social, } \\
\text { performa- } \\
\text { tividad y } \\
\text { accionismo } \\
\text { urbano. } \\
\text { Necesidades } \\
\text { y demandas. } \\
\text { Requeri- } \\
\text { mientos / } \\
\text { recursos / } \\
\text { condicionan- } \\
\text { tes. }\end{array}$ & $\begin{array}{l}\text { Eficiencia } \\
\text { tecnológica. } \\
\text { Flujos de } \\
\text { inversión. } \\
\text { Recursos } \\
\text { humanos. } \\
\text { Fabricantes } \\
\text { y proveedo- } \\
\text { res. }\end{array}$ & $\begin{array}{l}\text { Patio central } \\
\text { / Panta } \\
\text { central / } \\
\text { Lineal. } \\
\text { Exento / } \\
\text { Adyacente. } \\
\text { Distribución } \\
\text { secuencial / } \\
\text { jerárquica. }\end{array}$ \\
\hline \multicolumn{10}{|l|}{ Equipamiento } \\
\hline \multicolumn{10}{|l|}{$\begin{array}{l}\text { Centro Cultural } \\
\text { del Bicentenario, CABA }\end{array}$} \\
\hline \multicolumn{10}{|l|}{$\begin{array}{l}\text { Museo del Bicentenario } \\
\text { ex Aduana Taylor, CABA }\end{array}$} \\
\hline \multicolumn{10}{|l|}{$\begin{array}{l}\text { Centro Cívico del } \\
\text { Bicentenario, Córdoba }\end{array}$} \\
\hline \multicolumn{10}{|l|}{ Ciudad Judicial, Salta } \\
\hline \multicolumn{10}{|l|}{$\begin{array}{l}\text { Parque y Centro Cívico } \\
\text { Terrazas del Portezuelo, } \\
\text { San Luis }\end{array}$} \\
\hline \multicolumn{10}{|l|}{$\begin{array}{l}\text { Paseo y Fiesta } \\
\text { del Bicentenario, CABA }\end{array}$} \\
\hline \multicolumn{10}{|l|}{ Tecnópolis, CABA } \\
\hline $\begin{array}{l}\text { Parque de la Memoria. } \\
\text { Monumento a las } \\
\text { Víctimas del Terrorismo } \\
\text { de Estado, Caba }\end{array}$ & & & & & & & & & \\
\hline
\end{tabular}

\section{Referencia}

Gris: señala el paradigma de mayor incidencia. 
grafismos o efectos viso-lumínicos en Tecnópolis y en las fiestas mayas de la Av. 9 de Julio. También se ve, aunque controlado, en la mansarda de luminosidad cambiante del Palacio de Correos devenido centro cultural.

El paradigma objetual coloca la forma como resultado de una deliberada enfatización de la objetualidad del edificio en tanto cosa materialmente determinada. Interesa por el modo en que opera la materialidad, tanto sea por densificación como por aligeramiento. El primer caso es el CCK, en particular, en el gran auditorio que se incorpora como una forma bulbosa, pétrea y concreta inscripta en el vacío central. El segundo se ejemplifica en la atenuación de la materialidad también pétrea del memorial, que parece diluirse en la vastedad de ambiente y en la topografía verde del parque. Es el caso también generado por la imagen cambiante y casi incorpórea de Tecnópolis y en los fastos de la Av. de Julio.

Finalmente, el paradigma semio-lingüístico entendido como persistencia de una concepción de forma entendida como comunicación social —icónica, indicial o simbólica-y como una codificación sintáctica, semántica y pragmática de elementos, se verifica en casi todos los casos, si bien con distintas intenciones: construcción de ícono urbano en Córdoba, de narrativas diversas, asociadas al paisaje modernidad en San Luis, la historia nacional en las fiestas del bicentenario, el terrorismo de Estado en el Parque de la Memoria o la modernidad digital en Tecnópolis. Sin embargo, la voluntad más o menos explícita de operar la forma arquitectónica como retórica comunicacional confronta con una sociedad ya descripta como individualista, privatista, proclive a los estímulos directos, a las narrativas lineales, sujeta a los imaginarios del consumo y al hedonismo cortoplacista, sociedad más sensible a lo prosaico que a lo simbólico.

Se abre una incógnita respecto de la recepción social de las obras que fueron propuestas con intención de representar simbólicamente valores de civismo, por brindar una imagen estimulante de la percepción sensible o por generar o reforzar efectos de centralidad en una ciudad desencontrada. La respuesta es negativa para lo primero, neutra en relación con la imagen y positiva por la centralidad, pero por la obvia razón de que todo equipamiento viene a satisfacer una necesidad y, por ende, es un foco de referencia. Se reconoce especialmente el valor de imagen de los nuevos edificios en aquellos casos, como los centros cívicos, de alto impacto icónico, ya que la presencia del equipamiento contribuye a elevar la autoestima ciudadana. 
Los casos presentados, si bien limitados, sostienen la hipótesis de que, en la actualidad, estas obras son objetos paradójicos en relación con la ciudad escindida y la cultura líquida. Si bien refuerzan la presencia del Estado consolidando un dominio público tradicional (el Estado proveedor, los equipamientos colectivos y los servicios públicos como derechos ciudadanos), sus impactos en el espacio público de la ciudad tanto celebran como denuncian esa presencia.

Siendo la ciudad un complejo de formas materiales, prácticas sociales y significados culturales en relaciones inestables, la valoración ciudadana de los equipamientos comentados es extremadamente relativa a quién (individuos cada vez menos proclives a asumirse como ciudadanos), cuándo (la oportunidad, las circunstancias, las eventualidades) y dónde (algunos barrios o ciudades son más estables que otros).

En síntesis, el edificio público de y en la ciudad escindida oscila entre los extremos de la apropiación y el rechazo, de la celebración y la indiferencia. En cualquier caso, queda claro que la arquitectura en el período de la poscrisis, sea como ejercicio de pensamiento, instrumentación de políticas de Estado, recurso propagandístico o construcción de una realidad concreta, se afianzó como fenómeno y proceso concomitante de las tensiones del mundo contemporáneo y sigue una práctica de sentido en la dispersión de sentidos de la ciudad escindida.

\section{Bibliografía}

ARROYO, Julio (2016) Del espacio público a lo público en la ciudad escindida. Desplazamientos epistemológicos y conflictos arquitectónicos [en línea]. 2006, Café de las Ciudades. N. ${ }^{\circ}$ 42. [Consultado 19 de enero de 2016]. Disponible en http://www.cafedelasciudades.com. ar/arquitectura_42.htm.

UN, Santa Fe.

(2011) Espacio público. Entre afirmaciones y desplazamientos. Ediciones

(2016). "Arquitectura urbana y espacio público". Ponencia presentada en el 1.e. Coloquio de Investigación I+P+M Investigación en el Proyecto y Morfología en Arquitectura, Facultad de Arquitectura y Urbanismo, Universidad Nacional de Tucumán, abril de 2015. 
BALLENT, Anahí; GORELIK, Adrián (2000). "El príncipe”. Block, N. ${ }^{\circ} 5$.

BAUMAN, Zygmunt (2002) Modernidad líquida. Fondo de Cultura Económica, México. BOBBIO, Norberto; MATTEUCCI, N.; PASQUINO, G. (2005) Diccionario de política. Siglo XXI, México.

BORJA, Jordi (2003). "El espacio público: ciudad y ciudadanía”. En Ramírez Kuri, Patricia (coord.) Espacio público y reconstrucción de ciudadanía, Porrúa-FLACSO, México.

CARRIÓN MENA, Fernando (2007). "Espacio público: punto de partida para la alteridad". En Segovia Olga (edit.). Espacios públicos y construcción social. Hacía un ejercicio de ciudadanía. Santiago de Chile, Ediciones SUR, 2007, ps. 79-97. Disponible en: http://works.bepress. com/fernando_carrion/174.

CASTELLS, Manuel (1988) La era de la información. Economía, sociedad y cultura. Volumen I: La sociedad red; volumen II: El poder de la identidad; volumen III: Fin de milenio. Alianza, Madrid.

DELGADO, Manuel (2011) El espacio público como ideología. Catarata, Madrid.

HARVEY, David (2000). Espaços de esperança. Loyola, São Paulo. 2004.

(2012). Rebel cities. From the Right to the City to the Urban Revolution. Verso, London/New York.

HALL, Peter (1986) Ciudades del mañana. Historia del urbanismo en el siglo XX. Ediciones del Serbal, Barcelona.

HERNÁNDEZ AJA, Agustín (2000). "Barrios y equipamientos públicos: esencia del proyecto democrático de la ciudad”. En: Documentación Social, N. ${ }^{\circ}$ 119: 79-93.

GARCÍA CANCLINI, Néstor (2005) Diferentes, desiguales y desconectados. Mapas de la interculturalidad. Gedisa, Barcelona.

MONTANER, Josep María y MUXI, Zaida (2011). Arquitectura y política. G. Gili, Barcelona. ROMERO, Luis A. Democracia, república y estado: cien años de experiencia política en la Argentina. [en línea]. [Consultado 5/02/2014] Disponible en http://historiapolitica.com/datos/biblioteca/laromero1.pdf.

al siglo XXI. Siglo XXI.

(2013) La larga crisis de la Argentina. Del siglo XX

SOJA, Edward (2010) Seeking Spatial justice. University of Minnesota Press, Minneapolis.

CEPAL (2010) Anuario estadístico de América Latina y el Caribe.

FRANCO CALDERÓN, A.; ZABALA CORREDOR, S. (2012). "Los equipamientos urbanos como instrumentos para la construcción de ciudad y ciudadanía”. En Dearq N.$^{\circ} 11$, diciembre de 2012. Bogotá, pp. 8-13. Disponible en http://dearq.uniandes.edu.co. 